\title{
Remote sensing of forest biophysical variables using HyMap imaging spectrometer data
}

\author{
Martin Schlerf $^{\mathrm{a}, *}$, Clement Atzberger ${ }^{\mathrm{b}}$, Joachim Hill ${ }^{\mathrm{a}}$ \\ ${ }^{a}$ University of Trier, Remote Sensing Department, Behringstrasse, D-54286 Trier, Germany \\ bInstitut National de la Recherche Agronomique, Site Agroparc, F-84914 Avignon, France
}

Received 3 June 2004; received in revised form 10 November 2004; accepted 16 December 2004

\begin{abstract}
This study systematically evaluated linear predictive models between vegetation indices (VI) derived from radiometrically corrected airborne imaging spectrometer (HyMap) data and field measurements of biophysical forest stand variables $(n=40)$. Ratio-based and soil-linerelated broadband VI were calculated after HyMap reflectance had been spectrally resampled to Landsat TM channels. Hyperspectral VI involved all possible types of two-band combinations of ratio VI (RVI) and perpendicular VI (PVI) and the red edge inflection point (REIP) computed from two techniques, inverted Gaussian Model and Lagrange Interpolation. Cross-validation procedure was used to assess the prediction power of the regression models. Analyses were performed on the entire data set or on subsets stratified according to stand age. A PVI based on wavebands at $1088 \mathrm{~nm}$ and $1148 \mathrm{~nm}$ was linearly related to leaf area index (LAI) $\left(R^{2}=0.67, \mathrm{RMSE}=0.69 \mathrm{~m}^{2} \mathrm{~m}^{-2}\left(21 \%\right.\right.$ of the $^{2}$ mean); after removal of one forest stand subjected to clearing measures: $R^{2}=0.77$, RMSE $=0.54 \mathrm{~m}^{2} \mathrm{~m}^{-2}$ (17\% of the mean). A PVI based on wavebands at $885 \mathrm{~nm}$ and $948 \mathrm{~nm}$ was linearly related to the crown volume (VOL) $\left(R^{2}=0.79\right.$, RMSE $\left.=0.52\right)$. VOL was derived from measured biophysical variables through factor analysis (varimax rotation). The study demonstrates that for hyperspectral image data, linear regression models can be applied to quantify LAI and VOL with good accuracy. For broadband multispectral data, the accuracy was generally lower. It can be stated that the hyperspectral data set contains more information relevant to the estimation of the forest stand variables LAI and VOL than multispectral data. When the pooled data set was analysed, soil-line-related VI performed better than ratio-based VI. When age classes were analysed separately, hyperspectral VI performed considerably better than broadband VI. Best hyperspectral VI in relation with LAI were typically based on wavebands related to prominent water absorption features. Such VI are related to the total amount of canopy water; as the leaf water content is considered to be relatively constant in the study area, variations of LAI are retrieved.
\end{abstract}

(C) 2005 Elsevier Inc. All rights reserved.

Keywords: Imaging spectrometry; Hyperspectral; Multispectral; Vegetation indices; Biophysical forest variables; LAI

\section{Introduction}

Most of the forests located in the midlatitudes of the Northern Hemisphere act as a carbon sink, however, with considerable spatial and temporal variations and uncertainties (Canadell et al., 2000; Schimel et al., 2000; Valentini et al., 2000). Quantifying the strength of the carbon sink for present or future times can be achieved through ecosystem

\footnotetext{
* Corresponding author: Tel.: +49 651 2014593; fax: +49 6512013815.

E-mail address: schlerf@uni-trier.de (M. Schlerf).
}

simulation models together with remotely sensed estimates of biophysical variables, such as leaf area index (LAI) (Wicks \& Curran, 2003). As such, there is a considerable interest in developing algorithms for the estimation of LAI from remotely sensed vegetation reflectance (Tian et al., 2002).

Forests are generally challenging targets as a consequence of architectural heterogeneity, clumping of optically active surfaces at multiple scales and spatial-temporal foliage dynamics. Remote sensing of forest biophysical variables such as LAI is further complicated by the contribution of understory vegetation, litter, soil, bark as 
well as plant and relief shadow, all of which influence the radiometric signal (Chen et al., 1999; Soudani et al., 2002; Spanner et al., 1990a).

A lot of research has been done on the estimation of forest LAI from remote sensing data within about the last 15 years. A selection of literature results is presented in Table 1. Most of these studies were carried out in western coniferous forests with large LAI gradients (Running et al., 1986; Spanner et al., 1990b; White et al., 1997). In coniferous forest plantations, the ranges in LAI are usually lower and relationships between LAI and vegetation indices (VI) may be disturbed as other biophysical stand characteristics (such as stem density, canopy closure, tree height, etc.) influence the reflectance signal (Danson \& Curran, 1993; Treitz \& Howarth, 1999).

Most of the studies on forests used one or two ratio-based VI, such as the simple ratio (SR) or the normalised difference vegetation index (NDVI), computed from broadband remote sensing data (Curran et al., 1992; Herwitz et al., 1990; Peterson et al., 1987; Spanner et al., 1990a,b). A systematic investigation on the performance of various broadband multispectral and narrow band hyperspectral vegetation indices has been done on agricultural crops
(Boegh et al., 2002; Broge \& Mortensen, 2002) and very recently, also in forests. For instance, Gong et al. (2003) estimated forest LAI using vegetation indices derived from Hyperion hyperspectral data. Lee et al. (2004) performed a comparative analysis of hyperspectral versus multispectral data for estimating LAI in four different biomes. Using canonical correlation analysis, the authors found that individual, narrow bands of AVIRIS data yielded better relationships with LAI than broadband data for grassland and forest biomes. Given the few studies undertaken, it is still not sufficiently investigated whether the high spectral resolution data offer advantages over broadband data. It was shown that the spectral bandwidth of the red and near infrared (nIR) bands commonly used to form the VI had a considerable influence on their specific values (Teillet et al., 1997). Therefore, it seems to be interesting to compare narrow band hyperspectral with broadband multispectral VI.

The overall aim of the work was to evaluate the information content of hyperspectral remote sensing data for the estimation of forest stand variables in comparison with broadband data. More specifically, the objectives were (i) to identify useful stand variables out of the measured ones or generate new stand variables that could be correlated

Table 1

A selection of literature results on the estimation of forest biophysical variables

\begin{tabular}{|c|c|c|c|c|c|c|}
\hline Sensor & VI/Method & Variable & Range & $N$ & Relation & Reference \\
\hline ATM & RVI/BRA & LAI (various conifers) & $1-16$ & 18 & $R^{2}=0.82$ & $\begin{array}{l}\text { (Running et al., 1986; } \\
\text { Peterson et al., 1987) }\end{array}$ \\
\hline $\mathrm{TM}$ & $\rho_{\mathrm{Red}}, \rho_{\mathrm{nIR}} / \mathrm{BRA}$ & LAI (aspen) & $0.5-3.5$ & 29 & No relation & (Badhwar et al., 1986) \\
\hline AVHRR & NDVI/BRA & LAI (various conifers) & $1-13$ & 19 & $R^{2}=0.70-0.79$ & (Spanner et al., 1990a) \\
\hline $\mathrm{TM}$ & NDVI/BRA & LAI (various conifers) & $1-16$ & 73 & $\mathrm{r}=0.60$ & (Spanner et al., 1990b) \\
\hline $\mathrm{TM}$ & RVI/BRA & LAI (pine) & $4-7$ & 15 & No relation & (Herwitz et al., 1990) \\
\hline $\mathrm{TM}$ & NDVI/BRA & LAI (pine) & $2-10$ & 16 & $\begin{array}{l}R^{2}=0.35-0.86, \\
\text { RMSE }=0.74\end{array}$ & (Curran et al., 1992) \\
\hline CASI & NDVI/MLR & LAI (various conifers) & $1-12$ & 30 & $R^{2}>0.80$, RMSE $<1.0$ & (Gong et al., 1995) \\
\hline $\begin{array}{l}\text { Helicopter- } \\
\text { borne data }\end{array}$ & REIP/BRA & $\begin{array}{l}\text { LAI (spruce) } \\
\text { LAI }\end{array}$ & $5-11$ & 14 & $r=0.91$ & (Danson \& Plummer, 1995) \\
\hline $\mathrm{TM}$ & $\begin{array}{l}\text { NDVI/BRA } \\
\text { RVI /BRA }\end{array}$ & $\begin{array}{l}\text { Crown closure } \\
\text { (various conifers) }\end{array}$ & $\begin{array}{l}0.5-3.5 \\
0.05-0.85\end{array}$ & 22 & $\begin{array}{l}R^{2}=0.38-0.66 \\
R^{2}=0.26-0.63\end{array}$ & Chen \& Cihlar, 1996 \\
\hline $\mathrm{TM}$ & $\begin{array}{l}\text { RVI/MLR } \\
\text { NDVI/MLR }\end{array}$ & LAI (various conifers) & $1.0-4.5$ & 10 & $\begin{array}{l}R^{2}=0.71 \\
R^{2}=0.91\end{array}$ & (Fassnacht et al., 1997) \\
\hline $\mathrm{TM}$ & RVI, NDVI /BRA & LAI (various vegetation types) & $2-15$ & 39 & $R^{2}=0.65-0.90$ & (White et al., 1997) \\
\hline $\mathrm{TM}$ & NDVI/BRA & LAI (various forest types) & $\begin{array}{l}\text { Not } \\
\text { specified }\end{array}$ & 17 & $\begin{array}{l}R^{2}=0.15 \text { (all species) } \\
R^{2}=0.93 \text { (conifers) }\end{array}$ & (Franklin et al., 1997) \\
\hline $\mathrm{TM}$ & CRM inversion & LAI (various vegetation types) & $0-7$ & $\begin{array}{l}\text { Not } \\
\text { specified }\end{array}$ & $\begin{array}{l}\text { LAI pattern in good } \\
\text { accordance to the } \\
\text { land use map }\end{array}$ & (Kuusk, 1998) \\
\hline $\mathrm{TM}$ & RSR/BRA & LAI (pine, spruce) & $0.5-6.0$ & 35 & $R^{2}=0.55-0.70$ & (Brown et al., 2000) \\
\hline AVHRR & $\begin{array}{l}\text { NDVI/BRA } \\
\text { VI3/BRA }\end{array}$ & LAI (pine, aspen, spruce) & $2.0-4.0$ & 10 & $\begin{array}{l}R^{2}=0.46 \\
R^{2}=0.76\end{array}$ & (Boyd et al., 2000) \\
\hline CASI & REIP/BRA & LAI (spruce, pine) & $3-12$ & 16 & $r=0.94$ & (Lucas et al., 2000) \\
\hline CASI & CRM inversion & LAI (various conifers) & $1.0-3.0$ & 20 & $R^{2}=0.51-0.86$ & (Hu et al., 2000) \\
\hline CASI & CRM inversion & LAI (pine) & $1.0-3.0$ & 20 & $R^{2}=0.16-0.67$ & (Fernandes et al., 2002) \\
\hline $\mathrm{TM}$ & CRM inversion & Cover (pine) & $0.1-1.0$ & 33 & $R=0.33-0.38$ & (Gemmell et al., 2002) \\
\hline AVHRR & RSR/BRA & LAI (various conifers) & $0.5-10.5$ & $>50$ & $\begin{array}{l}R^{2}=0.62 \\
\text { RMSE }=1.48\end{array}$ & (Chen et al., 2002) \\
\hline
\end{tabular}

Sensors: ATM — airborne thematic mapper, TM—-thematic mapper, AVHRR—advanced very high resolution radiometer, CASI—compact airborne spectral imager; vegetation index (VI): RVI—ratio vegetation index, NDVI—normalised difference vegetation index, RSR—reduced simple ratio, REIP—red edge inflection point, $\mathrm{VI} 3=(\mathrm{nIR}-\mathrm{mIR}) /(\mathrm{nIR}+\mathrm{mIR})$; method: BRA—bivariate regression analysis, MLR—multiple linear regression, CRM—canopy reflectance model. 
with reflectance, (ii) to determine spectral VI that are best suited for characterising those stand variables and (iii) to compare and contrast traditional broadband and hyperspectral VI in terms of basic statistical characteristics of the predicted stand variables relative to the observed stand variables. The research was restricted to Norway spruce as only forest stands of this single species occur at a sufficient number within the selected test site.

\section{Material and methods}

\subsection{Study site and field measurements}

The Idarwald forest $\left(49^{\circ} 45^{\prime} \mathrm{N}, 7^{\circ} 10^{\prime} \mathrm{E}\right)$ is located on the north-western slopes of the Hunsrück mountain ridge, Germany. It covers an area of about 7500 ha. The terrain elevation in the study area ranges from 400 to $800 \mathrm{~m}$ above sea level. In 1999, 42 relatively homogenous Norway spruce (Picea abies) stands were identified at the Idarwald study area. Within these stands, 42 square 0.09 ha plots were established. The central location of each ground plot was determined with an accuracy of about $\pm 5 \mathrm{~m}$ using a differential global positioning system (GPS). Signal distortion within the forest stands did not give as high accuracies as specified by the manufacturer. From a total of 42 stands, one was not covered by the HyMap imagery, and another one was thinned in the period between ground data collection and the HyMap overpass. These two stands were excluded from the analysis reducing the data set to 40 stands.

At each plot, measurements of forest biophysical parameters were carried out during summer and autumn of 2000. Biophysical parameters measured include leaf area index (LAI), stem density (DEN), canopy closure (COV), perimeter at breast height $(\mathrm{PBH})$ and stand height (HEI). LAI was estimated using a Li-Cor LAI-2000 Plant Canopy Analyser (PCA). The LAI-2000 PCA estimates effective LAI using measurements of diffuse solar radiation above and below the forest canopy. Several factors such as sky conditions, topography, foliage clumping, woody materials and plant phenology all affect LAI estimates (Fournier et al., 2003). The LAI-2000 was only operated under overcast sky conditions during 10-16 h daytime. A $270^{\circ}$ view restrictor was used on the sensor. Within each plot, below canopy measurements were taken at 10 regularly spaced points from which the average was calculated. As no second device was available to operate the LAI-2000 in a two-sensor mode, above the canopy measurements were taken in a nearby open field before entering the plots. It was carefully paid attention to stable sky conditions between the open field and plot measurements. None of the outer rings were eliminated in the gap-fraction inversion. Despite the non-random distribution of leaves, no corrections for shoot level clumping and stand level clumping were applied. Also no contributions of woody surfaces were subtracted as the influence of woody components on the measurements is difficult to assess. It was assumed that the underestimation of LAI due to clumping effects was somehow compensated by the overestimation of LAI through woody structures (Fournier et al., 2003). As no corrections were applied, the retrieved LAI-2000 PCA measurements represent an effective plant area index instead of the real leaf area index. In the following sections these measurements are named effective leaf area index and abbreviated as LAI.

DEN was obtained by counting the number of trees in a plot. COV was visually estimated in steps of 5\% crown closure. $\mathrm{PBH}$ is defined as the trunk perimeter at $1.3 \mathrm{~m}$ above the forest ground. It was measured for 10 randomly selected trees within each plot and the stand average was calculated. HEI was calculated from the mean height of three dominant trees that were randomly selected within each plot. The height of each tree (from the ground to the top) was estimated from angular measurements. As forest stands at Idarwald consist of trees of the same age, dominant trees within a stand have similar heights. Hence, the selection of three trees to represent HEI was considered to be appropriate.

Assuming that the volume of a single stem can be approximated by a cone, a new variable stem biomass (SBM, unit: $\mathrm{t} \mathrm{ha}^{-1}$ ) was calculated from $\mathrm{PBH}$, HEI and DEN:

$\mathrm{SBM}=\frac{\pi\left(\frac{\mathrm{PBH}}{2 \pi}\right)^{2} \cdot \mathrm{HEI}}{3} \cdot \mathrm{DEN} \cdot \delta_{\mathrm{WOOD}}$

where $\delta_{\text {WOOD }}$ is the density of fresh wood (for Norway spruce: $0.47 \mathrm{~g} / \mathrm{cm}^{3}$ at $12-15 \%$ moisture content, Sedlmayer, 2004). Additionally, a variable related to crown volume (VOL) was generated from factor analysis (Section 3.1).

To improve LAI mapping, it has been suggested to derive land cover specific VI-LAI relationships using land cover maps (Chen et al., 2002; Cohen et al., 2003; Franklin et al., 1997). This statistical stratification of sampled stands is usually based on the species type. As in the present study just one single species is considered, it was decided to stratify the data set according to stand age (Table 2). Information about stand age was provided by a Forest Geographic Information System (FoGIS) that had been compiled for the Idarwald (Vohland, 1997).

\subsection{Image data and processing}

The hyperspectral HyMap sensor, designed and built by Integrated Spectronics, Australia, has the following speci-

Table 2

Resulting subsets after stratification according to forest stand age

\begin{tabular}{lllll}
\hline Subset & Designation & Abbreviation & Age [years] & $n$ \\
\hline 1 & Total (pooled dataset) & $t$ & $10-148$ & 40 \\
2 & Medium to old & $m o$ & $30-148$ & 35 \\
3 & Old & $o$ & $80-148$ & 17 \\
4 & Medium & $m$ & $30-79$ & 18 \\
5 & Young & $y$ & $10-29$ & 5 \\
\hline
\end{tabular}


fications: the instrument collects data in across-track direction by mechanical scanning and in along-track direction by movement of the airborne platform. Its instantaneous field of view (IFOV) is $2.5 \mathrm{mr}$ along-track and $2.0 \mathrm{mr}$ across-track and the field of view (FOV) is $60^{\circ}$ (512 pixels). The swath width at altitudes of 2000-5000 m above ground level is 2.3 to $4.6 \mathrm{~km}$ and the ground resolution 5 to $10 \mathrm{~m}$ (along-track). A complete spectrum over the range of $0.45-2.48 \mu \mathrm{m}$ is recorded in a sampling interval of 13-17 $\mathrm{nm}$ by 4 spectrographic modules. Each spectrographic module provides 32 spectral channels giving a total of 128 spectral measurements for each image pixel. Ground-based measurements of SNR indicated a peak signal-to-noise ratio of 1000:1 or better (Cocks et al., 1998).

HyMap was flown over the Idarwald test site at 17th July 1999. The data were recorded at 13:00 h Central European Time at an average flying height of $1980 \mathrm{~m}$ above ground level and free of cloud cover. The resulting ground resolution was about $5 \mathrm{~m}$ with a full scene covering approximately $3 \mathrm{~km} \times 10 \mathrm{~km}$. The flight line was run in a NE-SW direction parallel to the mountain ridge. From the original data cube with 128 bands between 400 and 2500 nm, 14 HyMap spectral channels with high noise were identified as bad bands and removed from the data set. Consequently, subsequent analyses were restricted to the remaining 114 bands.

Sensors with a large total field of view are typically affected by changes in the sensor view angle (Kennedy et al., 1997). To determine the magnitude of these effects, the digital numbers (DN) representing coniferous forest were plotted against image pixel number in the across scan direction (Fig. 1). A systematic increase of DNs with view angle in the down-Sun viewing direction and a decrease in the opposite-Sun viewing direction was observed. This well-known trend can be attributed to the effect of anisotropy and canopy shadow. As most vegetation canopies show a backward scattering characteristic the backlit side of the scanned image receives less reflected energy than the forlit side (Hildebrandt, 1996). To correct this view angle effect an across-track illumination correction was applied to each spectral band independently (ENVI 3.4, Research Systems). For this purpose, the image pixels representing coniferous forest were averaged by across-track position. The centre pixel was treated as correct. A second-order polynomial was fitted to the data. Based on the fitted polynomials, a normalisation procedure was applied. The corrected data showed almost no variation with change in across-track position, though a slight increase in DN at the very right side of the image could be observed (Fig. 1).

Additional radiometric correction of remote sensing imagery is exceptionally important for coniferous forests, as the small reflectance signal generated by conifer canopies is strongly influenced by terrain and atmospheric effects (Peterson \& Running, 1989). When quantitative attributes are to be estimated from remote sensing data, surface reflectance is the preferred or required data type (Peddle et al., 2003).

Atmospheric correction of the HyMap data sets was achieved with an in-house developed software package (AtCPro 3.01) which is originally based on the formulation of radiative transfer in 5S and 6S (e.g., Tanré et al., 1990). For an efficient and fast correction of image data acquired with multi- or hyperspectral sensors this code has been modified and extended, i.e., by integrating modules to account for varying terrain height and sensor altitude (Hill \& Sturm, 1991), to estimate the aerosol optical thickness directly from dark objects in the image (Hill, 1993) and to correct for illumination effects (Hill et al., 1995). Recently, the software package has been refined to cope with specific
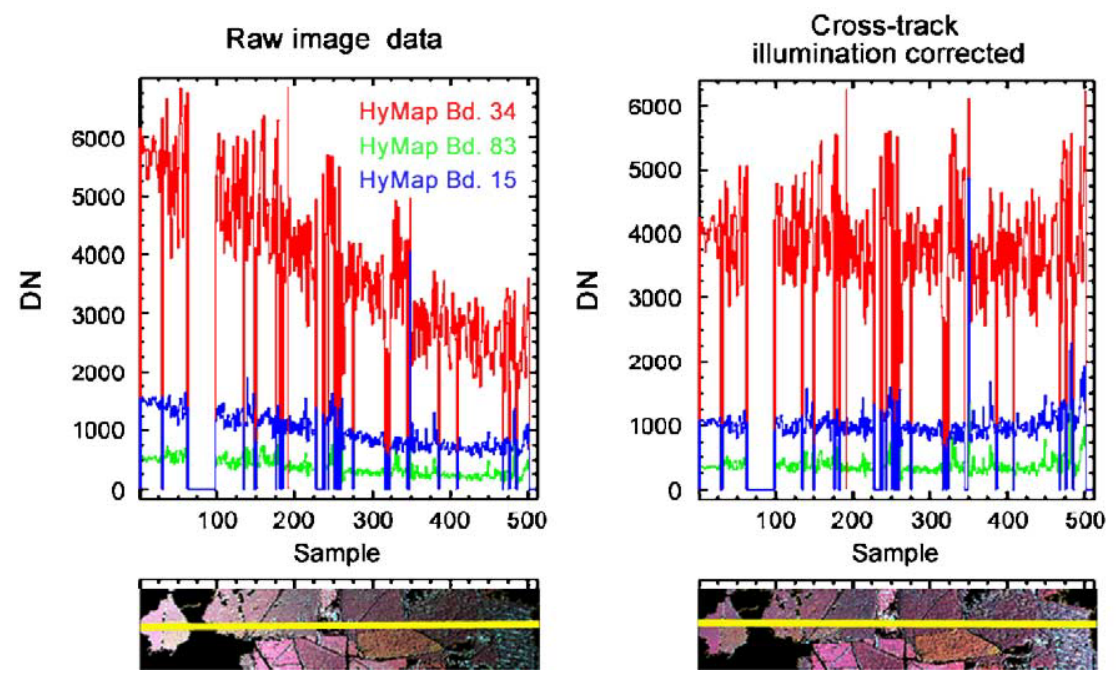

Fig. 1. Raw (left) and cross-track illumination corrected (right) image HyMap profiles (upper part) and corresponding portions of the HyMap scene (lower part). The yellow lines in the images indicate the course of the profiles. Profiles are shown for the red (Bd. 15), nIR (Bd. 34) and mIR (Bd. 83) domains. Images are displayed at band combination 34-83-15 (RGB). 
requirements of airborne hyperspectral image data by adding a module that, taking up concepts originally developed by Gao and Goetz (1990), produces spatially distributed maps of atmospheric water vapour to be included into the atmospheric correction (Hill \& Mehl, 2003).

The atmospheric correction of the HyMap data set considered in this paper further refers to information collected for a specific calibration flight performed during the same day in another area only $30 \mathrm{~km}$ away from the Idarwald study site. There, measurements of atmospheric beam transmittance were conducted with a CIMEL photometer between 6:00 and 12:00 GMT of June 10, 1999 (i.e., during the time of both flights). Their evaluation yielded an aerosol optical depth of $\tau_{\mathrm{a}}=0.33$ at $\lambda=0.550 \mu \mathrm{m}$ (i.e., a horizontal visibility of approximately $15 \mathrm{~km}$ ). Contemporarily, bi-directional reflectance measurements from 11 carefully selected ground targets with different surface characteristics (gravel, asphalt, dense lawn and water) were collected with an ASD FieldSpec II instrument to reconstruct, in combination with the derived aerosol optical depth and a water vapour concentration of $3.8 \mathrm{~g} / \mathrm{cm}^{2}$ (iterative approximation based on several MODTRAN runs), a set of updated HyMap in-flight calibration coefficients. It turned out that, except for single noisy bands with limited radiometric performance (e.g., band $1=0.403 \mu \mathrm{m}$, all bands $>2.410 \mu \mathrm{m}$ ) the resulting adjustments remained within $\pm 15 \%$ of the HyMap pre-flight calibration values. Using these updated calibration coefficients with our extended implementation of 5S (AtCPro 3.01) it was possible to reconstruct a spatially differentiated water vapour map for the HyMap scene acquired over Idarwald which, in a final run, was integrated into the atmospheric correction processing of this image. This correction also included a correction for terrain induced illumination effects, for which specific DEM-derivates (slope, aspect and the proportion of the visible hemispherical sky at each pixel) had been transferred to the geometry of the original HyMap image using the parametric image processing software PARGE developed by Schläpfer et al. (1998). The visual impression of relief present in the raw data was removed after applying the topographic correction. The obtained reflectance spectra indicated a good data quality, ensuring a sound basis for quantitative data exploration.

The image data were geometrically corrected using the parametric geocoding software PARGE (Schläpfer et al., 1998). For this purpose, the required DEM with an original pixel size of $20 \mathrm{~m}$ was resampled to $5 \mathrm{~m}$ using bilinear interpolation. Thirty ground control points measured in the field by differential GPS were used to calibrate the in-flight auxiliary data. Image resampling was performed using triangulation coding from centre pixels (Schläpfer et al., 1998). The RMS error of the geometric correction was 4.3 $\mathrm{m}$ in $x$-direction and $4.8 \mathrm{~m}$ in $y$-direction. With an image pixels size of $5 \mathrm{~m}$, the geometric correction was accurate to within a pixel.
Reflectance spectra were extracted from the image data for the forest stands under investigation. Only pixels located within circles of certain radii $(7 \mathrm{~m}, 12 \mathrm{~m}, 17 \mathrm{~m}$, $22 \mathrm{~m}, 32 \mathrm{~m}, 42 \mathrm{~m}$ and $52 \mathrm{~m}$ ) around the central position of the field plots were included. Pixels not representing spruce forest were cut out from the circles through a GISoperation resulting in circle segments. Mean and standard deviation of spectral reflectance were obtained for seven radii. Coefficient of variation was plotted against radius (not shown). Values of the variation coefficient were lowest at a radius of $42 \mathrm{~m}$. Therefore, for most of the forest stands, a radius of $42 \mathrm{~m}$ was considered to be the critical size from where local heterogeneity is not further increasing. For all forest stands, mean reflectance spectra were extracted from the image using pixels of $42-\mathrm{m}$ radius around the central position.

\subsection{Computation of VI}

Both, hyperspectral and broadband VI were computed from the radiometrically corrected HyMap imagery (114 spectral bands).

\subsubsection{Broadband VI}

Ratio-based and soil-line-related (orthogonal) broadband VI (see Table 3 for definitions) were calculated after the HyMap data had been resampled to Landsat TM spectral bands involving the appropriate Landsat TM5 filter functions; the ratio-based VI were SR and NDVI; the orthogonal VI were PVI and TSAVI; additional VI were MVI, and GVI.

\subsubsection{Hyperspectral VI}

Hyperspectral indices were computed for RVI and PVI involving all possible two-band combinations of 114 channels. Additionally, the red edge inflection point (REIP) was calculated using two different methods, the inverted Gaussian Model (IGM), and the Lagrange Interpolation (LGI).

2.3.2.1. Narrow band VI. The narrow band RVI and PVI were systematically calculated for all possible $114 \times$ $114=12,996$ band combinations. RVI was computed according to

$\mathrm{RVI}=\frac{\rho_{\mathrm{Bd} 1}}{\rho_{\mathrm{Bd} 2}}$

PVI requires site-specific soil line slopes (a) and intercepts (b). As no soil spectral data was available, soil line parameters were fixed to arbitrary values $(a=0.9 ; b=0.1)$ :

$\mathrm{PVI}=\frac{\rho_{\mathrm{Bd} 1-a \rho_{\mathrm{Bd} 2}}-b}{\sqrt{1+a^{2}}}$

It was assumed that the soil line concept, originally defined for the red-nIR feature space, can be transferred into other spectral domains (Thenkabail et al., 2000). Hence, it was supposed that soil lines exist between all wavebands. 
Table 3

Broadband vegetation indices investigated in this study

\begin{tabular}{|c|c|c|c|}
\hline Name & Abbreviation & Equation & Reference \\
\hline Simple ratio & SR & $\frac{\rho_{\mathrm{TM} 4}}{\rho_{\mathrm{TM} 3}}$ & (Pearson and Miller, 1972) \\
\hline Normalised difference vegetation index & NDVI & $\frac{\rho_{\mathrm{TM} 4}-\rho_{\mathrm{TM} 3}}{\rho_{\mathrm{TM} 4}+\rho_{\mathrm{TM} 3}}$ & (Rouse et al., 1974) \\
\hline Perpendicular vegetation index & PVI & $\frac{\rho_{\mathrm{TM} 4}-a \rho_{\mathrm{TM} 3}-b}{\sqrt{1+a^{2}}}$ & (Richardson \& Wiegand, 1977) \\
\hline Transformed soil-adjusted vegetation index & TSAVI & $\begin{array}{l}a=0.9, b=0.1 \\
\frac{a\left(\rho_{\mathrm{TM} 4}-a \rho_{\mathrm{TM} 3}-b\right)}{a \rho_{\mathrm{TM} 4}+a \rho_{\mathrm{TM} 3}-a b} \\
a=0.9, b=0.1\end{array}$ & (Baret et al., 1989) \\
\hline Mid-infrared vegetation index & MVI & $\frac{\rho_{\mathrm{TM} 4}}{\rho_{\mathrm{TM} 5}}$ & (Fassnacht et al., 1997) \\
\hline Greenness vegetation index & GVI & $\begin{array}{l}-0.2848 \rho_{\mathrm{TM} 1}-0.2435 \rho_{\mathrm{TM} 2} \\
-0.5436 \rho_{\mathrm{TM} 3}+0.7243 \rho_{\mathrm{TM} 4} \\
+0.0840 \rho_{\mathrm{TM} 5}-0.1800 \rho_{\mathrm{TM} 7}\end{array}$ & (Christ \& Cicone, 1984) \\
\hline
\end{tabular}

$\rho$-reflectance, TM-thematic mapper.

2.3.2.2. Red edge inflection point. The red edge inflection point (REIP) has been used to indicate vegetation stress and senescence (Horler et al., 1983; Rock et al., 1988). The REIP depends on the amount of chlorophyll seen by the sensor (Dawson \& Curran, 1998). The chlorophyll amount present in a vegetation canopy is characterised by the chlorophyll content of the leaves and the leaf area index (LAI). Danson and Plummer (1995) suggested that the REIP should provide a useful tool for LAI estimations particularly for taking advantage of high spectral resolution data. In previous work, Atzberger and Werner (1998) studied the spatial variation of leaf chlorophyll concentration $\left(\mathrm{C}_{a+b}\right)$ at Idarwald test site on the basis of 39 Norway spruce stands. They found that the inter-stand variation of $\mathrm{C}_{a+b}$ was relatively low (mean $=4.22 \mathrm{mg} \mathrm{g}^{-1}$ dry matter, standard deviation $=1.00 \mathrm{mg} \mathrm{g}^{-1}$ dry matter). This can be attributed to the rather poor nutrient supply of the soils, derived from the underlying schist and quartzite rocks prevalent to the entire region. It is therefore concluded that the chlorophyll amount present in the spruce canopies is determined more by the LAI than by leaf chlorophyll concentration and that the REIP can be related to LAI.

The REIP was computed using two different approaches, inverted Gaussian model (IGM) and Lagrange Interpolation (LGI). IGM (Bonham-Carter, 1988) describes the variations of reflectance $R_{\text {est }}$ as a function of wavelength $(\lambda)$ at the red edge as follows:

$R_{\text {est }}(\lambda)=R_{\mathrm{S}}-\left(R_{\mathrm{S}}-R_{0}\right) \cdot e^{\frac{\left(\lambda-\lambda_{0}\right)^{2}}{2 \sigma^{2}}}$

where $R_{\mathrm{s}}$ is the reflectance maximum ("shoulder" reflectance), usually at approximately $780-800 \mathrm{~nm} ; R_{0}$ is the reflectance minimum, usually at about $670-690 \mathrm{~nm} ; \lambda_{0}$ is the wavelength of the reflectance minimum; $\sigma$ is the Gaussian shape parameter with unit nanometre. The red edge inflection point REIP $_{\text {IGM }}$ is then derived as $\mathrm{REIP}_{\mathrm{IGM}}=\lambda_{0}+\sigma$. The IGM method fits a Gaussian normal function to the reflectance at the red edge and the estimated REIP is then the midpoint on the ascending part of the modelled curve. The function is fitted through the measured reflectance data points $R_{\text {mes }}(\lambda)$ by adjusting the values of $R_{\mathrm{s}}$, $R_{0}, \lambda_{0}$ and $\sigma$ in such a way that the root-mean-square error (RMSE) is minimized.

LGI (Dawson \& Curran, 1998) is applied to the approximate first derivative of the reflectance spectrum, which is computed as follows:

$D_{\text {mes }}\left(\lambda_{j}\right)=\frac{R\left(\lambda_{j+1}\right)-R\left(\lambda_{j}\right)}{\lambda_{j+1}-\lambda_{j}}$

where $D_{\text {mes }}\left(\lambda_{j}\right)$ is the measured first derivative transformation at the midpoint with wavelength $j$ between the wavebands $j$ and $j+1 ; R\left(\lambda_{j}\right)$ and $R\left(\lambda_{j+1}\right)$ are the reflectances at the bands $j$ and $j+1$, respectively. A second order polynomial is fitted directly to three bands of the first-order derivative spectrum (Dawson \& Curran, 1998):

$$
\begin{aligned}
D_{\mathrm{est}}(\lambda)= & \frac{\left(\lambda-\lambda_{i}\right) \cdot\left(\lambda-\lambda_{i+1}\right)}{\left(\lambda_{i-1}-\lambda_{i}\right) \cdot\left(\lambda_{i-1}-\lambda_{i+1}\right)} \cdot D_{\mathrm{mes}}\left(\lambda_{i-1}\right) \\
& +\frac{\left(\lambda-\lambda_{i-1}\right) \cdot\left(\lambda-\lambda_{i+1}\right)}{\left(\lambda_{i}-\lambda_{i-1}\right) \cdot\left(\lambda_{i}-\lambda_{i+1}\right)} \cdot D_{\mathrm{mes}}\left(\lambda_{i}\right) \\
& +\frac{\left(\lambda-\lambda_{i-1}\right) \cdot\left(\lambda-\lambda_{i}\right)}{\left(\lambda_{i+1}-\lambda_{i-1}\right) \cdot\left(\lambda_{i+1}-\lambda_{i}\right)} \cdot D_{\mathrm{mes}}\left(\lambda_{i+1}\right)
\end{aligned}
$$

where $D_{\text {est }}(\lambda)$ is the first derivative estimated by the LGI model at any wavelength $\lambda ; \lambda_{i}$ is the band having the maximum first derivative; $\lambda_{i-1}$ and $\lambda_{i+1}$ are the bands on the left and right side of $\lambda_{i}$, respectively; $D_{\text {mes }}\left(\lambda_{i}\right), D_{\text {mes }}\left(\lambda_{i-1}\right)$ and $D_{\text {mes }}\left(\lambda_{i+1}\right)$ are the measured first derivative values. The REIP is located at the wavelength $\operatorname{REIP}_{\text {LGI }}$ were $D_{\text {est }}(\lambda)$ is maximum; to determine this position (and thus, the position of maximum slope of reflectance), the first derivation on $D_{\text {est }}(\lambda)$ is performed, representing the second derivative of the reflectance. The equation is resolved, for when the first 
Table 4

Summary statistics for forest stand variables $(n=40)$

\begin{tabular}{|c|c|c|c|c|c|c|}
\hline & Mean & Standard deviation & Maximum & Minimum & Range & Coefficient of variation \\
\hline $\mathrm{PBH}[\mathrm{m}]$ & 1.09 & 0.32 & 1.63 & 0.27 & 1.36 & 0.294 \\
\hline DEN $\left[\mathrm{ha}^{-1}\right]$ & 640 & 458 & 2444 & 244 & 2200 & 0.716 \\
\hline $\operatorname{COV}[\%]$ & 48 & 11 & 70 & 30 & 40 & 0.229 \\
\hline HEI [m] & 25.1 & 7.9 & 39.1 & 5.0 & 34.1 & 0.315 \\
\hline LAI $\left[\mathrm{m}^{2} \mathrm{~m}^{-2}\right]$ & 3.24 & 0.97 & 5.47 & 1.66 & 3.81 & 0.299 \\
\hline $\mathrm{SBM}\left[\mathrm{t} \mathrm{ha}{ }^{-1}\right]$ & 201 & 109 & 654 & 11 & 643 & 0.54 \\
\hline
\end{tabular}

derivative of $D_{\text {est }}(\lambda)$ is zero, giving (Dawson \& Curran, 1998):

$\operatorname{REIP}_{\mathrm{LGI}}=\frac{A \cdot\left(\lambda_{i}+\lambda_{i+1}\right)+B \cdot\left(\lambda_{i-1}+\lambda_{i+1}\right)+C \cdot\left(\lambda_{i-1}+\lambda_{i}\right)}{2 \cdot(A+B+C)}$

where

$$
\begin{aligned}
& A=\frac{D_{\mathrm{mes}}\left(\lambda_{i-1}\right)}{\left(\lambda_{i-1}-\lambda_{i}\right) \cdot\left(\lambda_{i-1}-\lambda_{i+1}\right)}, \\
& B=\frac{D_{\mathrm{mes}}\left(\lambda_{i}\right)}{\left(\lambda_{i}-\lambda_{i-1}\right) \cdot\left(\lambda_{i}-\lambda_{i+1}\right)}, \\
& C=\frac{D_{\mathrm{mes}}\left(\lambda_{i+1}\right)}{\left(\lambda_{i+1}-\lambda_{i-1}\right) \cdot\left(\lambda_{i+1}-\lambda_{i}\right)}
\end{aligned}
$$

\subsection{Regression models}

A widely used empirical approach for modelling the relationship between two variables is regression analysis (Cohen et al., 2003). Commonly, one variable is difficult or costly to measure (e.g., LAI from field sampling) and the other is relatively inexpensive to measure (e.g., VI from remote sensing). VI is often related to LAI through a linear or exponential regression model, depending on the presence of saturation effects. However, the saturation of VI with increasing LAI depending on tree species and canopy structure is not sufficiently investigated (anonymous reviewer). For conifers it has been shown that linear regression models seem to be appropriate as saturation occurs only at relatively high densities. For instance, Peterson et al. (1987) found that the saturation level was reached at an LAI of approximately 8 in the red domain. Other results suggest a saturation of the NDVI at an LAI of about 5 (Chen \& Cihlar, 1996; Turner et al., 1999) or no saturation effect at all in the case of the RVI (Chen et al., 2002). Therefore, in this study, linear regression was employed to evaluate the relationships between biophysical stand variables and VI.

\subsection{Validation}

We used the cross-validation procedure to validate the regression models. Cross-validation is a method of assessing the accuracy and validity of a calibration model. This required for each regression variant to develop 40 separate models, each time with data from 39 observations. The calibration model was then used to predict the observation that was left out. Because the predicted samples are not the same as the samples used to build the model, the crossvalidated RMSE is a good indicator of the accuracy of the model in predicting unknown samples. Another advantage of cross-validation is its ability to detect outliers. If the predicted observations for a single sample is far off the measured observation, the sample is probably an outlier (Duckworth, 1998).

\section{Results and discussion}

\subsection{Forest stand variables}

From the summary statistics (Table 4), it can be seen that the variables $\mathrm{PBH}, \mathrm{COV}$ and LAI have a similar variability, whereas COV is less variable and SBM and DEN are more variable. The large variability of DEN can be attributed to the extraordinary large density values of young forest stands.

Table 5 lists linear correlation coefficients between forest stand variables. Strong relationships between stand variables were found for PBH, DEN and HEI. These variables are closely related to stand age; with increasing age, trees grow in height and diameter and PBH and HEI increase, while DEN is reduced due to thinning. An inverse relationship can be observed between LAI and age. The inverse relation between LAI and stand age seems to be related to the fact that during stand development, crowns of individual trees expand and increase utilization of available growing space. The point at which crowns of different trees begin to interact is considered as being the peak LAI after which a

Table 5

Linear correlation between forest stand variables $(n=40)$

\begin{tabular}{lrrrrrr}
\hline & PBH & DEN & COV & HEI & LAI & SBM \\
\hline PBH & 1.00 & & & & & \\
DEN & $-0.87^{*}$ & 1.00 & & & & \\
COV & $-0.55^{*}$ & $0.72 *$ & 1.00 & & & \\
HEI & $0.88^{*}$ & $-0.86^{*}$ & $-0.58^{*}$ & 1.00 & & \\
LAI & $-0.72 *$ & $0.72^{*}$ & $0.68^{*}$ & $-0.70 *$ & 1.00 & \\
SBM & $0.81^{*}$ & $-0.59^{*}$ & -0.20 & $0.80 *$ & $-0.48^{*}$ & 1.00 \\
AGE & $0.85^{*}$ & $-0.72 *$ & $-0.49 *$ & $0.82^{*}$ & $-0.66^{*}$ & $0.77^{*}$ \\
\hline
\end{tabular}

* Correlation coefficient significant at $P<0.01$. 


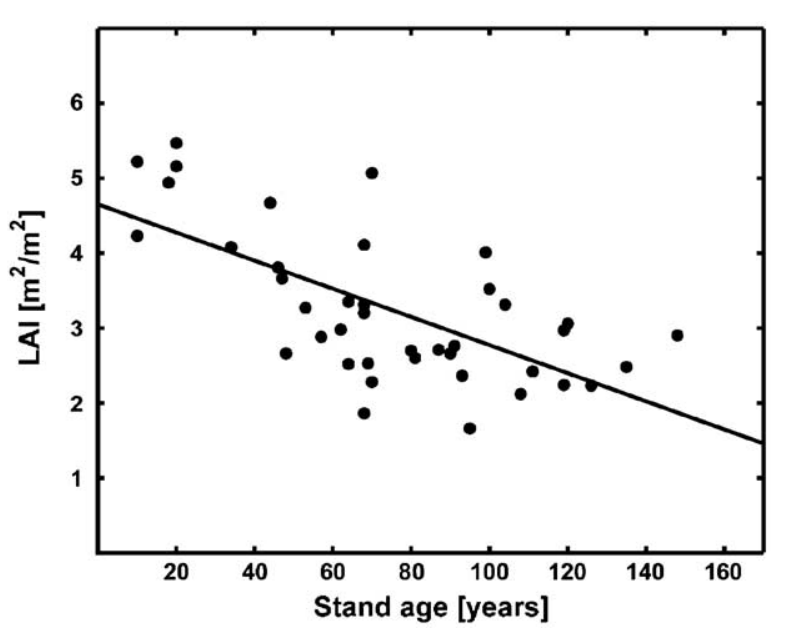

Fig. 2. LAI as a function of stand age for Norway spruce stands at Idarwald test site $(n=40)$.

rapid decrease takes place due to competition between the individual trees (Vose et al., 1994). It has been shown that stands of slow growing species (Pinus contora) reached its maximum LAI at age 40 and that it lasted for about 30 years (Long and Smith, 1992).

Prevalent forestry practices in Germany aim to maximise the profitability of a site. Thinning, the extraction of some of the young trees in a forest so that the remainder grow and develop fully, has an additional, major influence on the temporal LAI dynamic. At Idarwald, after a maximum LAI value at an age of 20-30 years is reached, stands of Norway spruce are usually thinned at an age of 30-50. Therefore, relatively low LAI values can be expected. After 60-70 years an increase in LAI may take place up to an age of 100 where logging can lead to gaps in the canopy cover. Depending on the application of thinning measures, maximum variation of LAI can be expected at age 30-70 (Vohland, 1997). In Fig. 2, LAI is plotted against stand age for the sampled Norway spruce stands of Idarwald test site. Here, a peak LAI can be assumed at an age of 20. From an age of 20 onwards, a gradual decline in LAI from up to age 150 is evident. Maximum variation of LAI occurs at age 6070. Obviously, some stands have been thinned lately whereas others have been thinned long time ago. After an increase of LAI up to age 100 a decrease of LAI is caused by gaps related to logging measures. It can be concluded that the observed age course of Norway spruce based on the probed sample is a result of both natural circumstances and actual management practices. It is also clear from Fig. 2 that LAI can vary considerably within a single age class and thus, information on LAI cannot simply be derived from an age class map.

At first, relationships between the forest stand variables and single band reflectance were examined (Table 6). The stand variables were most strongly correlated with TM4, and less correlated with TM3 and TM5. Correlations were positive for DEN, COV and LAI and negative for PBH, HEI and SBM. PBH, DEN and HEI were more strongly correlated with reflectance whereas COV, LAI and SBM were less correlated with reflectance. Attributes related to canopy cover (LAI, COV) are usually expected to have negative correlations with red reflectance. At Idarwald, we found weak positive correlations between LAI and red reflectance (TM3). However, red reflectance varied only between 2.7 and $3.0 \%$ and possibly, saturation in the red has already occurred at low LAI values. Another explanation could be that green leaves and the underlying soil and litter have similar reflectances in the red and that an increase in LAI or COV would not have an influence on red reflectance. Finally, effects of shading could be responsible that old stands of relatively low LAI also have low reflectances in the red domain. One could also expect negative correlations between LAI and reflectance in the mIR (TM5) (Brown et al., 2000). Although we found such negative correlations for wavebands located in the water absorption features, we observed positive correlations for wavebands located at the reflectance maximum between the $1.4-\mu \mathrm{m}$ and $1.9-\mu \mathrm{m}$ water absorption features. Again, shading could be a possible explanation for these findings.

The correlation coefficients $(r)$ between biophysical variables and both reflectance and first derivative reflectance spectra are presented as correlograms (Fig. 3). The strength of the relation generally decreased from nearinfrared (nIR) to mid-infrared (mIR) wavebands and was greater for first derivative reflectance spectra in opposition to reflectance spectra. The decreasing $r$ values with increasing wavelength from the nIR to the mIR reflected the decrease in signal-to-noise ratio of the data. In this respect the correlograms were similar to those reported in other studies (e.g., Curran et al., 2001). Correlations were positive throughout all wavelength regions for DEN, COV and LAI and negative for PBH, HEI and SBM. The nIR region of reflectance spectra revealed strongest correlations followed by the green peak, the mIR region, and the chlorophyll absorption features in the red and blue wavebands. For the correlation between reflectance and LAI, similar curves were obtained in other studies (Thenkabail et al., 2000). However, one major difference was the positive correlation between LAI and reflectance in the red which has been already discussed in the previous paragraph.

From the strong intercorrelations between the stand variables (Table 5), it was evident that no single variable

Table 6

Linear correlation between forest stand variables and HyMap reflectance resampled to TM spectral bands $(n=40)$

\begin{tabular}{lccc}
\hline & TM3 & TM4 & TM5 \\
\hline PBH & $-0.60^{* *}$ & $-0.80^{* *}$ & $-0.55^{* *}$ \\
DEN & $0.72^{* *}$ & $0.86^{* *}$ & $0.66^{* *}$ \\
COV & $0.41^{* *}$ & $0.69^{* *}$ & $0.38^{*}$ \\
HEI & $-0.57^{* *}$ & $-0.84^{* *}$ & $-0.57^{* *}$ \\
LAI & $0.36^{*}$ & $0.76^{* *}$ & $0.33^{*}$ \\
SBM & $-0.50^{* *}$ & $-0.64^{* *}$ & $-0.51^{* *}$ \\
\hline
\end{tabular}

* Correlation coefficient significant at $P<0.05$.

** Correlation coefficient significant at $P<0.01$. 

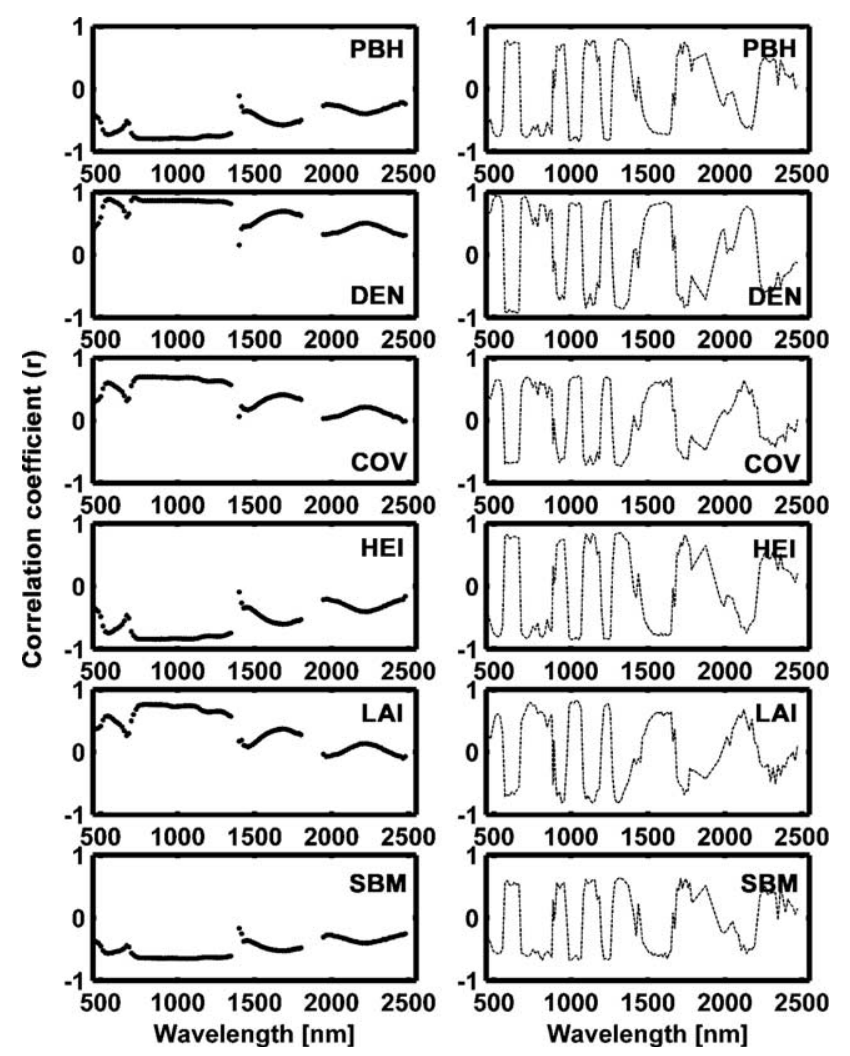

Fig. 3. Correlograms $(r)$ for six biophysical stand variables and both reflectance (left) and first derivative reflectance (right) spectra $(n=40)$. Data points in first derivative reflectance correlograms are plotted as lines for clarity.

could be regarded as causal to the reflectance in the TM bands. Therefore, the principal components (PC) were computed on the forest stand variables to reduce the data and generate new variables that could be correlated with reflectance. The input variables were standardised to zero mean and unit standard deviation. From the five original variables (all variables except SBM) five PC were derived. The first 3 PC explained more than $95 \%$ of the variability of the original data set. The eigenvectors of $\mathrm{PC} 1$ revealed moderately large positive loadings on PBH and HEI and a moderately large negative loading on DEN. While principal components analysis is often preferred as a method for data reduction, principal factors analysis is often chosen when the goal of the analysis is to detect structure. Unlike principal components analysis, in principal factors analysis we only use the variability in a stand variable that it has in common with the other stand variables. The goal of the various existing rotational strategies is to obtain a clear pattern of loadings, that is factors that are clearly marked by high loadings for some variables and low loadings for others (Harman, 1976; StatSoft, Inc., 2004).

The factor analysis was computed using the varimax rotation. Again, the input variables were standardised to zero mean and unit variance. After standardisation, one common factor (CF) was computed from the five original stand variables (Table 7). The $p$-value of 0.08 failed to reject
Table 7

Statistics of the first component factor of the varimax rotation (CF1) compared to the Eigenvector of the first principal component PC1 $(n=40)$

\begin{tabular}{llcc}
\hline Stand variable & Specific variance CF1 & Loading CF1 & Loading PC1 \\
\hline PBH & 0.1268 & -0.9345 & 0.4638 \\
DEN & 0.1275 & 0.9341 & -0.4757 \\
COV & 0.5400 & 0.6782 & -0.3972 \\
HEI & 0.1417 & -0.9265 & 0.4633 \\
LAI & 0.4107 & 0.7677 & -0.4315 \\
\hline
\end{tabular}

the null hypothesis of one common factor suggesting that this model provides a satisfactory explanation of the covariation in these data. A specific variance of 1 would indicate that there is no common factor component in that variable, while a specific variance of 0 would indicate that the variable is entirely determined by common factors. The estimated specific variances indicated that the stand variables $\mathrm{PBH}, \mathrm{DEN}$, and $\mathrm{HEI}$ are determined by the common factor. However, the common factor did not clearly represent the variables LAI and COV. For interpretation of the common factor, its loading has to be examined (Table 7). CF1 has very high loadings on the variables PBH, DEN and HEI, but only moderately high loadings on LAI and COV. The loadings obtained by CF1 reveal a much clearer pattern than those obtained by PC1. According to the loadings of $\mathrm{CF} 1$, old stands consisting of large trees at low density would have low scores on CF1. It was obvious, to interpret $\mathrm{CF} 1$ as a variable that is inversely related to stand age. The correlation between CF1 and stem biomass was moderately strong $(r=-0.74)$. Following an interpretation by Danson and Curran (1993), CF1 was regarded as a variable inversely related to crown volume (VOL).

In a next step, the common factor and the principal components were correlated with the reflectance data in the TM bands (Table 8). Statistically significant positive relationships were found between CF1 and TM reflectance. This indicated that stands for which a high reflectance was recorded had a high score on CF1 and thus, a low VOL. Also PC1 showed a close relationship to TM reflectance. No correlations were observed between PC of higher order and reflectance. From Fig. 4 it is evident that CF1 is closely related to stand age. While up to stand age 60 a linear relationship can be observed, saturation starts at higher age, resulting in an exponential relation between stand age and CF1.

A similar increase with stand age has also been observed for total biomass in boreal spruce (P. abies) forests

Table 8

Linear correlation between the common factor and principal components and HyMap reflectance resampled to TM spectral bands $(n=40)$

\begin{tabular}{lccc}
\hline & TM3 & TM4 & TM5 \\
\hline CF1 & $0.65^{*}$ & $0.88^{*}$ & $0.61^{*}$ \\
PC1 & $-0.61^{*}$ & $-0.89^{*}$ & $-0.57^{*}$ \\
PC2 & -0.18 & -0.02 & -0.19 \\
PC3 & -0.29 & -0.02 & -0.28 \\
\hline
\end{tabular}

* Correlation coefficient significant at $P<0.01$. 


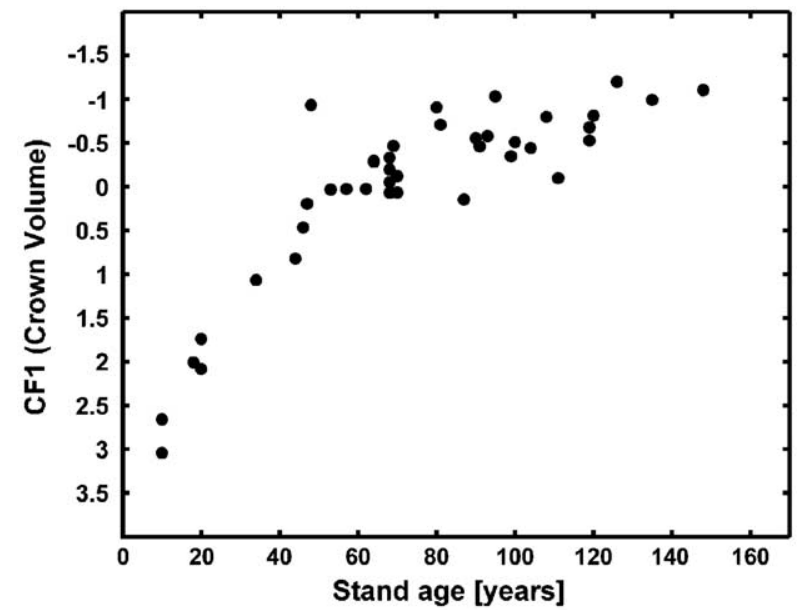

Fig. 4. First common factor (CF1) as a function of stand age for Norway spruce stands at Idarwald test site $(n=40)$. A low value of CF1 corresponds to a large crown volume.

(Kazimirov \& Morozova, 1973) but saturation did not occur before age 120. This relationship between stand age and total biomass was compared to the relationship between stand age and stem biomass (SBM). When SBM is plotted against stand age, apart from one extreme observation a curvilinear relationship is observed, but even at high age no saturation occurs (Fig. 5). The outlier is the oldest of all sampled stands (age $=148$ years). In these stands very large values of HEI and PBH and moderately large values of DEN were measured resulting in very large values of SBM. Despite a relatively large correlation coefficient between VOL and SBM of -0.74 , VOL and SBM were considered as dissimilar variables in the subsequent analysis mainly due to their different dependence on stand age.

\subsection{VI relationships with forest stand variables}

Most of the linear regression models indicated that the best relationships were obtained using LAI or VOL; the regression with $\mathrm{PBH}$, HEI and DEN also provided several good relations but were not considered due to their strong intercorrelation; $\mathrm{COV}$ was not considered due to the strong relation to LAI. Thus, the results presented restrict to LAI, VOL and SBM.

\subsubsection{Narrow band VI}

To determine optimal narrow band VI, coefficients of determination $\left(R^{2}\right)$ between all possible two-band VI and forest stand variables were computed. The results are illustrated in 2D-correlation plots (Fig. 6). Each point at position (band 1, band 2) in the upper triangle of Fig. 6 represents the $R^{2}$ value between LAI and the RVI calculated from the reflectance values in that two wavebands. The lower triangle of Fig. 6 highlights band combinations where $R^{2}$ was larger than 0.75. Similar correlation plots to the one in Fig. 6 were computed for the other biophysical variables. Based on the $R^{2}$ values in the
2D-correlation plots, band combinations that formed the best indices were determined for LAI, VOL and SBM. These were considered as optimal indices and were named RVI_opt and PVI_opt. Up to three best performing indices were considered when they occurred in different wavelength regions. For example, in Fig. 6, the indices that have highest correlation with LAI were identified in the lower triangle of the 2D-correlation plot: the three most dominant indices occur in the regions around $1346 \mathrm{~nm} /$ $1207 \mathrm{~nm}, 1134 \mathrm{~nm} / 920 \mathrm{~nm}$ and $1802 \mathrm{~nm} / 1163 \mathrm{~nm}$ (red marks). The band positions were then tabulated in Table 9. For the best performing narrow band index, cross-validated $R^{2}$ and RMSE were computed (Table 10).

\subsubsection{Broadband VI}

The first step in the analysis of broadband VI was to compare ratio to soil-adjusted VI and to compare VI based on Visible and nIR reflectance to those based on mIR and nIR reflectance. Broadband ratio VI (RVI and NDVI) generally showed relatively low values of $R^{2}$ and relatively high values of RMSE for all subsets. The soil-adjusted broadband models (PVI and TSAVI) performed significantly better for the pooled data set; obviously, background effects related to soil and litter were reduced. Whereas younger stands revealed a denser canopy with little background contribution to the signal, in older stands with gaps and a more open canopy the background may had a larger influence on reflectance. Hence, when the total age dynamic is considered, TSAVI and PVI performed better than RVI or NDVI but when age classes were considered separately, no performance increase was observed. The findings of Brown et al. (2000), that soiladjusted VI compared to the RVI have a decreased sensitivity to forest LAI, could not be confirmed.

Broadband MVI was closer related to LAI and VOL than broadband RVI and NDVI (subset $m$ and $m o$ ). The mIR band in combination with the nIR band seemed to contain more information relevant to the characterisation of forest canopies than the combination of red and nIR bands. A

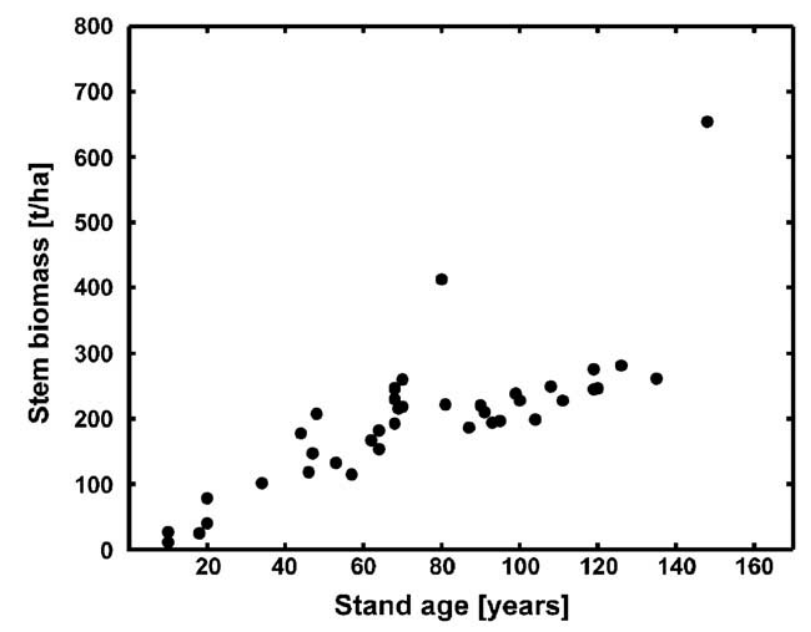

Fig. 5. Stem biomass (SBM) as a function of stand age for Norway spruce stands at Idarwald test site $(n=40)$. 

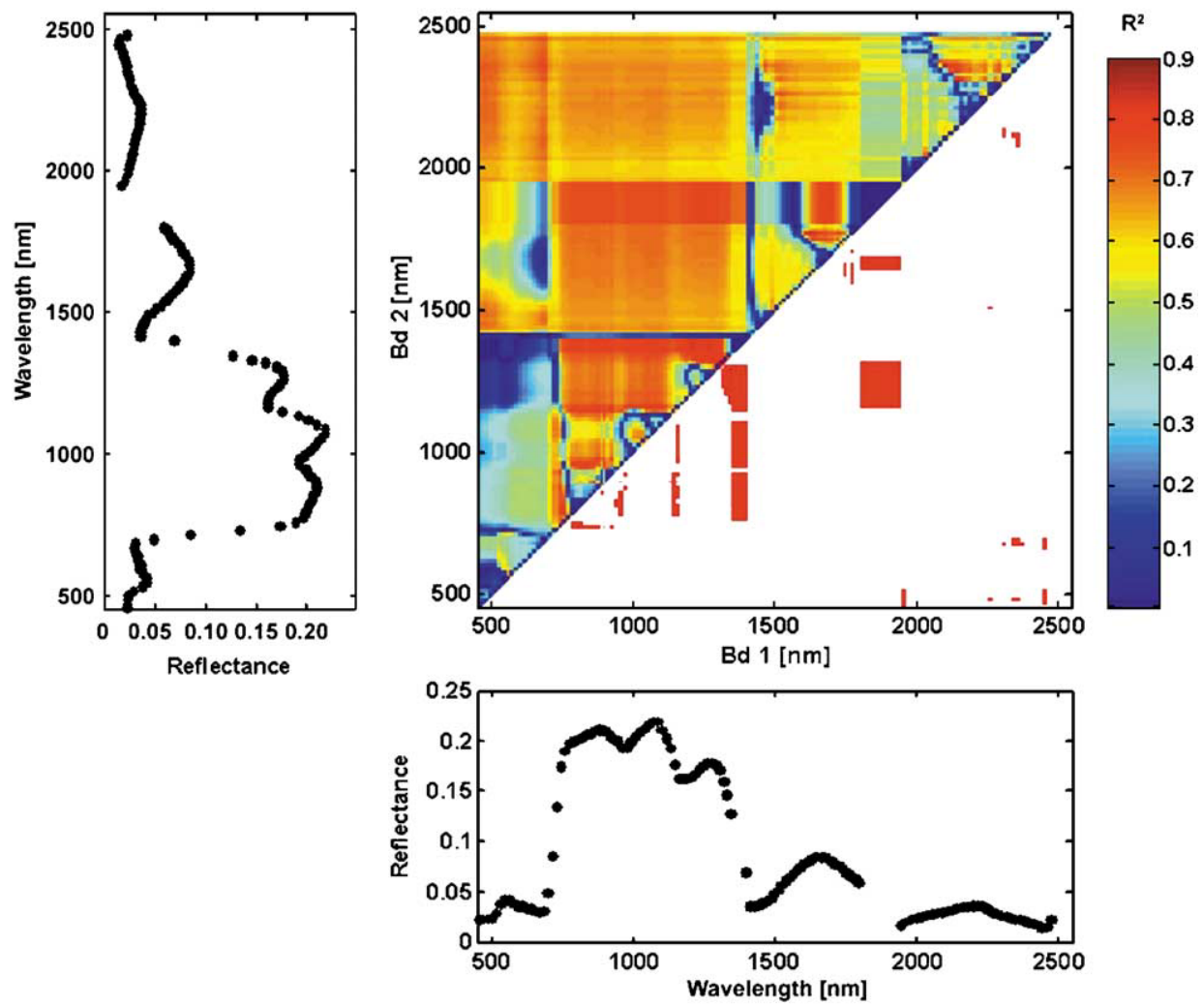

Fig. 6. 2D-correlation plot that shows the correlation $\left(R^{2}\right)$ between LAI and narrow band RVI values (subset $m$ ). The matrix is symmetrical; therefore just values above the diagonal are displayed. Below the diagonal, band combinations are marked in red where $R^{2}>0.75$. The displayed average reflectance spectrum of all measured forest plots eases the interpretation of the 2D-correlation plot. As the HyMap spectrum is not continuous, large squares of $R^{2}$ values may belong to single wavebands.

closer relation of forest LAI to radiation in the mIR than to radiation in the Visible was found by Boyd et al. (2000) for tropical vegetation; the authors put forward that this could be the case also with boreal forests. The results found in the present study also support the suggestion by Fassnacht et al. (1997) that mIR bands may improve LAI estimation, particularly in more open forest stands. Recently, Lee et al. (2004) stretched the importance of spectral channels in the red edge and mIR regions in predicting LAI of different biomes.

\subsubsection{Broadband versus hyperspectral VI}

In the second step of the analysis, broadband VI was compared to hyperspectral VI to see if hyperspectral indices improve the prediction accuracy. All best narrow band RVI (RVI_opt) and PVI (PVI_opt) performed better

Table 9

Best narrow band RVI and PVI derived from 2D-correlation plots for different subsets

\begin{tabular}{|c|c|c|c|c|c|c|c|c|c|}
\hline & & \multicolumn{2}{|c|}{ Subset $t(10-148$ years $)$} & \multicolumn{2}{|c|}{ Subset mo $(30-148$ years $)$} & \multicolumn{2}{|c|}{ Subset $o(80-148$ years $)$} & \multicolumn{2}{|c|}{ Subset $m(30-79$ years $)$} \\
\hline & & $\lambda[\mathrm{nm}]$ & $r^{2}$ & $\lambda[\mathrm{nm}]$ & $r^{2}$ & $\lambda[\mathrm{nm}]$ & $r^{2}$ & $\lambda[\mathrm{nm}]$ & $r^{2}$ \\
\hline \multirow[t]{6}{*}{ LAI } & RVI_opt & $918 / 965$ & 0.65 & $896 / 965$ & 0.68 & $747 / 807$ & 0.60 & $1346 / 1207$ & 0.85 \\
\hline & & $850 / 680$ & 0.55 & $1802 / 1043$ & 0.65 & & & $1134 / 920$ & 0.85 \\
\hline & & $1165 / 750$ & 0.60 & $1346 / 1119$ & 0.65 & & & $1802 / 1163$ & 0.80 \\
\hline & & $1088 / 1148$ & 0.70 & & & & & $918 / 1134$ & 0.83 \\
\hline & PVI_opt & & & $895 / 1134$ & 0.64 & $1445 / 2060$ & 0.56 & $1320 / 1220$ & 0.82 \\
\hline & & $1148 / 807$ & 0.70 & & & & & $2220 / 457$ & 0.72 \\
\hline \multirow[t]{2}{*}{ SBM } & RVL_opt & $472 / 1119$ & 0.31 & $933 / 747$ & 0.31 & $2354 / 2337$ & 0.50 & $1279 / 1264$ & 0.53 \\
\hline & PVI_opt & 777/900 & 0.46 & 933/747 & 0.32 & $2337 / 2354$ & 0.41 & $948 / 747$ & 0.46 \\
\hline \multirow[t]{5}{*}{ VOL } & RVI_opt & $671 / 702$ & 0.74 & $996 / 1058$ & 0.60 & $2385 / 2042$ & 0.51 & $1011 / 1028$ & 0.74 \\
\hline & PVI_opt & $981 / 1058$ & 0.82 & $1073 / 981$ & 0.60 & $2320 / 2449$ & 0.41 & $1073 / 996$ & 0.69 \\
\hline & & $1417 / 1070$ & 0.82 & & & & & & \\
\hline & & $948 / 885$ & 0.82 & & & & & & \\
\hline & & $747 / 457$ & 0.82 & & & & & & \\
\hline
\end{tabular}

Each vegetation index is formed by a pair of wavebands. The wavelength positions and the coefficients of determination $\left(r^{2}\right)$ between the indices and the biophysical variables are given. Subset $y$ was excluded from the analysis due to the small number of samples. 
Table 10

Cross-validated $R^{2}$ (first line) and cross-validated RMSE (second line) for linear regression between broadband and hyperspectral (narrow band VI and REIP) indices and forest stand variables LAI and VOL

\begin{tabular}{|c|c|c|c|c|c|c|c|c|c|}
\hline & \multirow[b]{2}{*}{$\begin{array}{l}\text { Subset } \\
n\end{array}$} & \multicolumn{4}{|l|}{ LAI } & \multicolumn{4}{|l|}{ VOL } \\
\hline & & $\begin{array}{l}t \\
40 \\
\end{array}$ & $\begin{array}{l}m o \\
35 \\
\end{array}$ & $\begin{array}{l}m \\
17 \\
\end{array}$ & $\begin{array}{l}o \\
18 \\
\end{array}$ & $\begin{array}{l}t \\
40 \\
\end{array}$ & $\begin{array}{l}m o \\
35 \\
\end{array}$ & $\begin{array}{l}m \\
17 \\
\end{array}$ & $\begin{array}{l}o \\
18 \\
\end{array}$ \\
\hline \multirow[t]{12}{*}{ Broadband VI } & \multirow[t]{2}{*}{ RVI } & 0.40 & 0.42 & 0.40 & 0.17 & 0.23 & 0.38 & 0.35 & 0.26 \\
\hline & & 1.23 & 0.92 & 1.05 & 1.67 & 1.9 & 1.7 & 2.9 & 1.9 \\
\hline & \multirow[t]{2}{*}{ NDVI } & 0.43 & 0.44 & 0.44 & 0.17 & 0.24 & 0.34 & 0.31 & 0.25 \\
\hline & & 1.13 & 0.86 & 0.95 & 1.72 & 1.8 & 1.7 & 2.8 & 1.9 \\
\hline & \multirow[t]{2}{*}{ PVI } & 0.57 & 0.29 & 0.23 & 0.22 & 0.76 & 0.35 & 0.35 & 0.10 \\
\hline & & 0.87 & 1.29 & 1.7 & 1.7 & 0.58 & 2.2 & 4.9 & 3.1 \\
\hline & \multirow[t]{2}{*}{ TSAVI } & 0.61 & 0.36 & 0.30 & 0.24 & 0.68 & 0.37 & 0.36 & 0.07 \\
\hline & & 0.80 & 1.06 & 1.35 & 1.55 & 0.69 & 1.8 & 3.6 & 3.9 \\
\hline & \multirow[t]{2}{*}{ MVI } & 0.38 & 0.54 & 0.58 & 0.35 & 0.19 & 0.51 & 0.45 & 0.15 \\
\hline & & 1.3 & 0.71 & 0.71 & 1.83 & 2.3 & 1.1 & 1.3 & 85.5 \\
\hline & \multirow[t]{2}{*}{ GVI } & 0.58 & 0.31 & 0.24 & 0.24 & 0.75 & 0.36 & 0.35 & 0.07 \\
\hline & & 0.85 & 1.2 & 1.62 & 1.55 & 0.59 & 2.1 & 4.7 & 3.8 \\
\hline \multirow[t]{8}{*}{ Hyperspectral VI } & \multirow[t]{2}{*}{ RVI_opt } & 0.62 & 0.64 & 0.77 & 0.57 & 0.70 & 0.59 & 0.70 & 0.45 \\
\hline & & 0.78 & 0.58 & 0.45 & 0.57 & 0.68 & 0.91 & 0.65 & 1.1 \\
\hline & \multirow[t]{2}{*}{ PVI_opt } & 0.67 & 0.45 & 0.41 & 0.52 & 0.79 & 0.58 & 0.64 & 0.38 \\
\hline & & 0.69 & 0.86 & 1.02 & 0.58 & 0.52 & 0.98 & 0.78 & 1.4 \\
\hline & \multirow[t]{2}{*}{ LGI } & 0.01 & 0.58 & 0.75 & 0.44 & 0.26 & 0.46 & 0.33 & 0.05 \\
\hline & & 400 & 0.64 & 0.49 & 0.66 & 5.8 & 1.1 & 1.6 & 16.2 \\
\hline & \multirow[t]{2}{*}{ IGM } & 0.00 & 0.58 & 0.72 & 0.47 & 0.27 & 0.43 & 0.27 & 0.00 \\
\hline & & 45 & 0.65 & 0.53 & 0.66 & 4.0 & 1.2 & 1.8 & 8.7 \\
\hline
\end{tabular}

The best VI are typed in bold. Relations with SBM were generally poor and are not listed. Subset $y$ was excluded from the analysis due to the small number of samples.

than the corresponding broadband VI. RMSE values of about $1 \mathrm{~m}^{2} \mathrm{~m}^{-2}$ or larger for regression models between broadband RVI and LAI (subsets $m o, o$ and $m$ ) decreased to values as low as $0.5 \mathrm{~m}^{2} \mathrm{~m}^{-2}$ for the optimal narrow band RVI. The improvement of the narrow band models compared to the broadband models was not that distinct in the case of the PVI. Regression between PVI and VOL over all age classes (pooled data set) revealed almost similar results for broadband and narrow band indices. The reason that some of the broadband results were high could be from having a very high signal-to-noise ratio (SNR). However, this does not mean that sensors like TM5 could be able to reproduce these results as they would have a much lower SNR.

Comparing narrow band orthogonal VI with ratio VI revealed that PVI_opt performed better than RVI_opt (pooled data set); for subsets $m o, m$ and $o$, however, RVI_opt showed lower RMSE values than PVI_opt for LAI and VOL. No correlation was observed between REIP (LGI and IGM) and LAI over the total age dynamic, but for subset $m$, LGI showed an RMSE value of less than $0.5 \mathrm{~m}^{2}$ $\mathrm{m}^{-2}$. This value is comparable to the RMSE value obtained between RVI_opt and LAI. These findings were partly supported by results obtained from other studies. Danson and Plummer (1995) found a strong non-linear correlation between plot LAI and the REIP for Sitka spruce (Picea sitchensis) using helicopter-borne spectroradiometer data. For the same tree species, forest LAI was recently related to the canopy REIP computed from imaging spectrometer data (CASI) with success (Lucas et al., 2000). Attempts to relate the chlorophyll content of canopies to the REIP were successful for grass canopies (Pinar \& Curran, 1996), but only partially successful for forest canopies (Curran et al., 1991). Blackburn (2002) found no relation between REIP and LAI for coniferous stands using CASI data.

In a summary, it was concluded that the best relationships between remotely sensed reflectance and forest stand variables were found using LAI and VOL. In a study on agricultural crops, Thenkabail et al. (2000) also found the

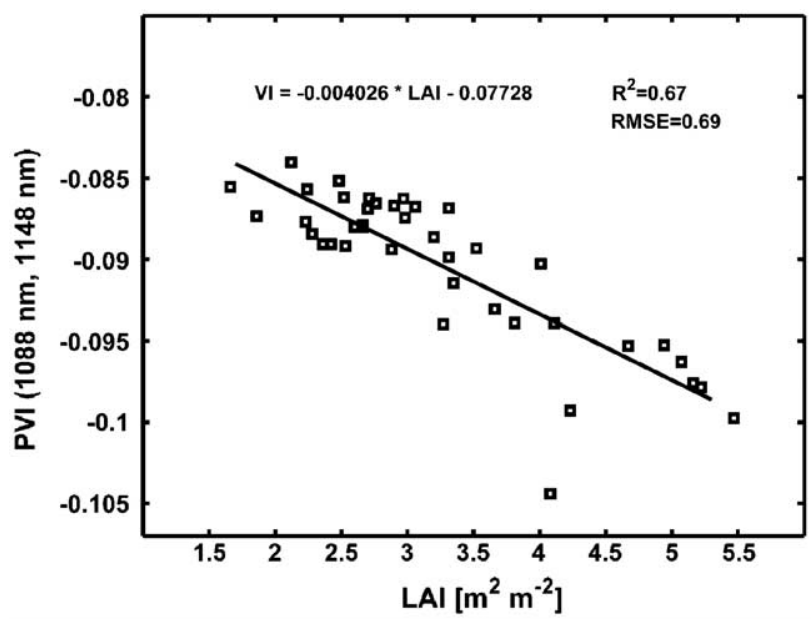

Fig. 7. Linear regression between best narrow band PVI and LAI. Values of $R^{2}$ and RMSE are cross-validated. When the outlier at position $4.1 /-0.104$ is removed, cross-validated $R^{2}$ increases to 0.77 and RMSE decreases to $0.54 \mathrm{~m}^{2} \mathrm{~m}^{-2}$. 


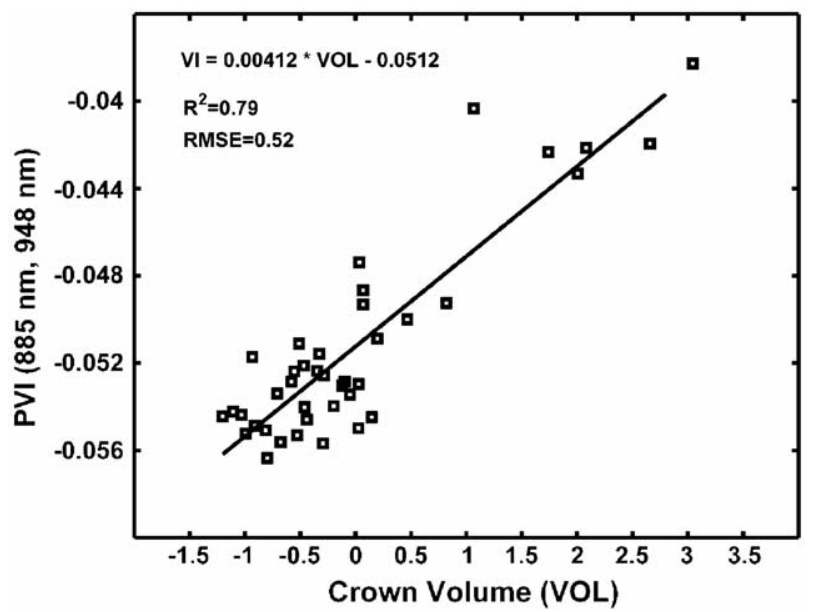

Fig. 8. Linear regression between best narrow band PVI and crown volume. Values of $R^{2}$ and RMSE are cross-validated. A high value of VOL corresponds to a low crown volume and vice versa.

closest relations between hyperspectral VI and LAI or biomass, whereas relationships with crop height, and canopy cover were generally not as good. The major result of the present study was that the hyperspectral data set contained more information relevant to the estimation of the forest stand variables LAI and VOL than multispectral data. Lee et al. (2004) came to the conclusion that regression models using AVIRIS channels performed better to predict LAI than those based on broadband data. However, the advantage of hyperspectral over multispectral data does not always seem to be the case: for instance, Broge and Mortensen (2002) came to the conclusion that hyperspectral VI derived from field spectral measurements were not better at estimating green crop area index (a variable related to LAI) than traditional broadband VI. Then again, these authors found that the prediction of canopy chlorophyll density was improved using narrow bands across the red edge. Results of the present study concerning old stands (subset $o$ ) show that relatively poor relationships were found in particularly for the broadband VI. Also other studies reported problems with old stands that have been ascribed to shadow effects and a relatively dark background in the nIR (Spanner et al., 1990a).
In the scatter plot between PVI_opt and LAI (Fig. 7), even at high values of LAI no saturation is evident. A closer look reveals an outlier at position 4.1/-0.104. The corresponding forest stand of age 34 was identified in the image data. Whereas the 1999 image showed no abnormality in reflectance, in recently acquired HyMap data of 2003, a striped pattern was detected. From the spectral reflectance properties, the image pixels representing stripes could be identified as a mixture between tree crowns and forest litter. The striping pattern was caused by open strips that had been cut into the forest between the image acquisition and field measurements. Open strips allowed for the employment of harvesters to remove trees that had been exposed to game bite (Womelsdorf G., Personal communication).

Also the relationship between PVI_opt and VOL (Fig. 8) is linear. In contrast to Fig. 7, two main clusters of data points can be identified. Those data points with a value of VOL larger than 1 refer to forest stands of an age less than 40 years.

\subsubsection{Water absorption features}

The best relations between both LAI and VOL and the optimal narrow band VI used PVI based on wavelength positions related to water absorption features. One of the two wavebands forming PVI_opt typically lay at the shoulder of the absorption feature, the other waveband lay at the absorption minimum (Fig. 9). Obviously, PVI_opt based on such wavebands is a measure of the total amount of canopy water $\left(M_{\mathrm{H} 20}\right)$ seen by the sensor. $M_{\mathrm{H} 20}$ (unit: $\mathrm{kg}$ water per $\mathrm{m}^{2}$ ground area) depends on both leaf water content (LWC; unit: $\mathrm{mg}$ water per $\mathrm{cm}^{2}$ leaf area) and leaf area index (LAI):

$M_{\mathrm{H}_{2} \mathrm{O}}=\mathrm{LWC} \cdot \mathrm{LAI}$

When LWC does not vary between forest stands, PVI_opt reflects spatial patterns of LAI.

\subsection{Maps of effective leaf area index and crown volume}

The best regression models that have been found for the estimation of LAI (Fig. 10) and VOL (Fig. 11) were applied to the HyMap image. Only image pixels representing

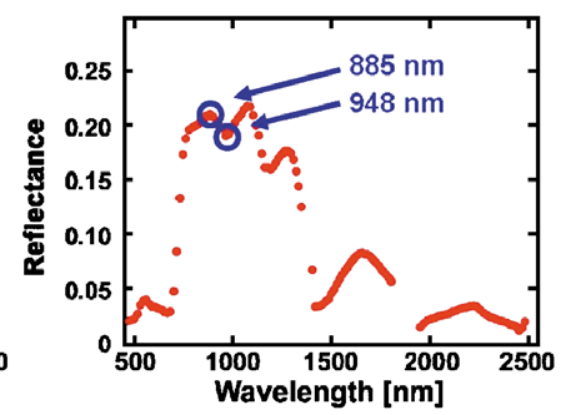

Fig. 9. Wavelength position of selected optimal narrow band VI for LAI (left) and VOL (right). Wavebands are associated with typical water absorption features. 


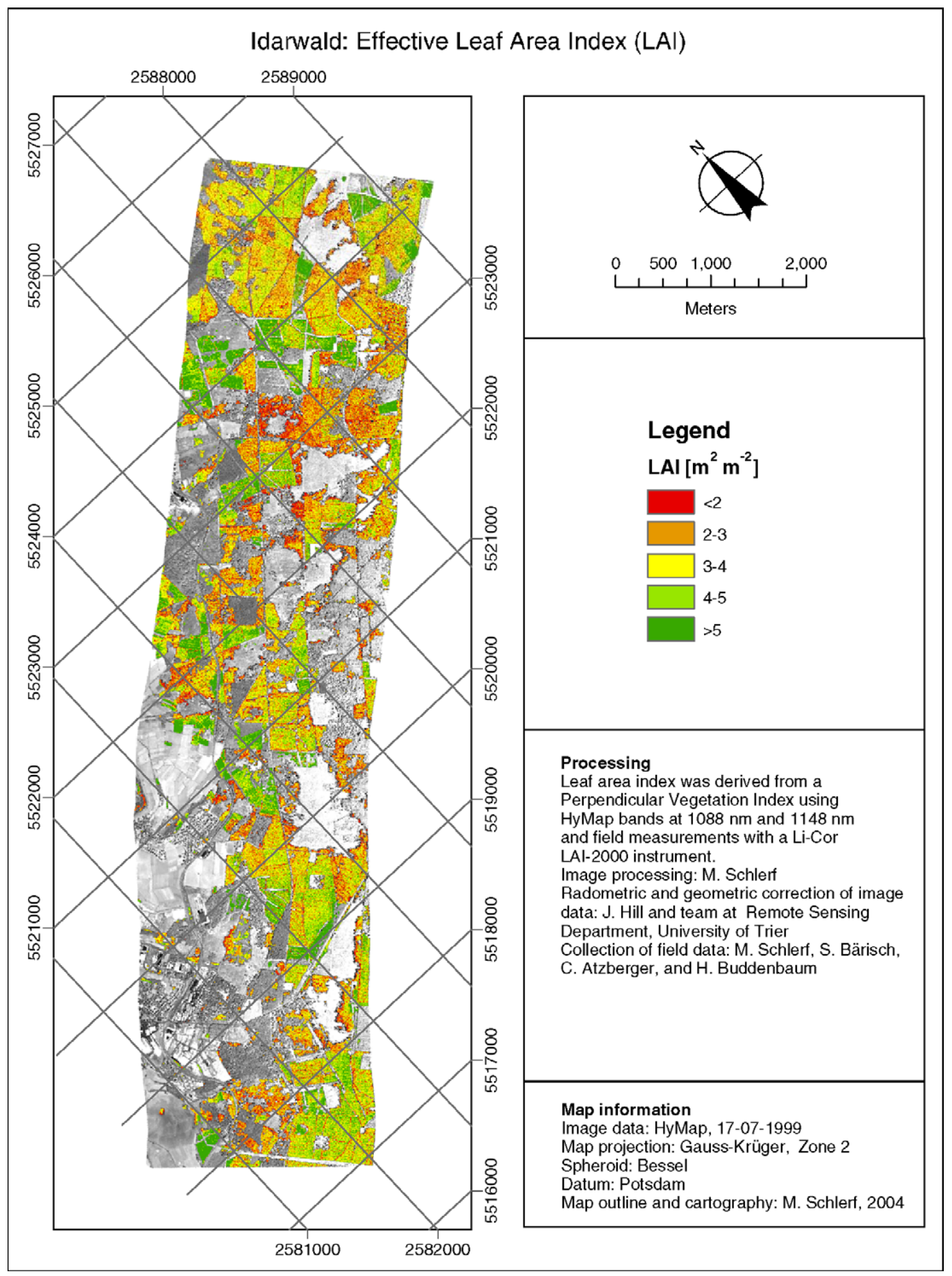

Fig. 10. Map of effective leaf area index at Idarwald.

coniferous forest were considered. Estimated values of LAI were generally in a reasonable range. LAI values were classified into five classes for cartographic reasons. Although most of the forest stands in the LAI map appear rather homogenous, certain variation within the stands can be observed. This reflects the fact that even in highly managed forests, stands do not develop evenly in space. From the interpretation of the spatial patterns prevalent in both parameter maps it can be seen that the values of the crown volume map are in general inversely related to the values of the LAI map. Young stands with low crown volume have not undergone thinning measures and reveal large LAI values and small crowns. Old stands with relatively low values of LAI have built up large tree crowns. From the resulting LAI map and the Forest Geographic Information System, average values of LAI 


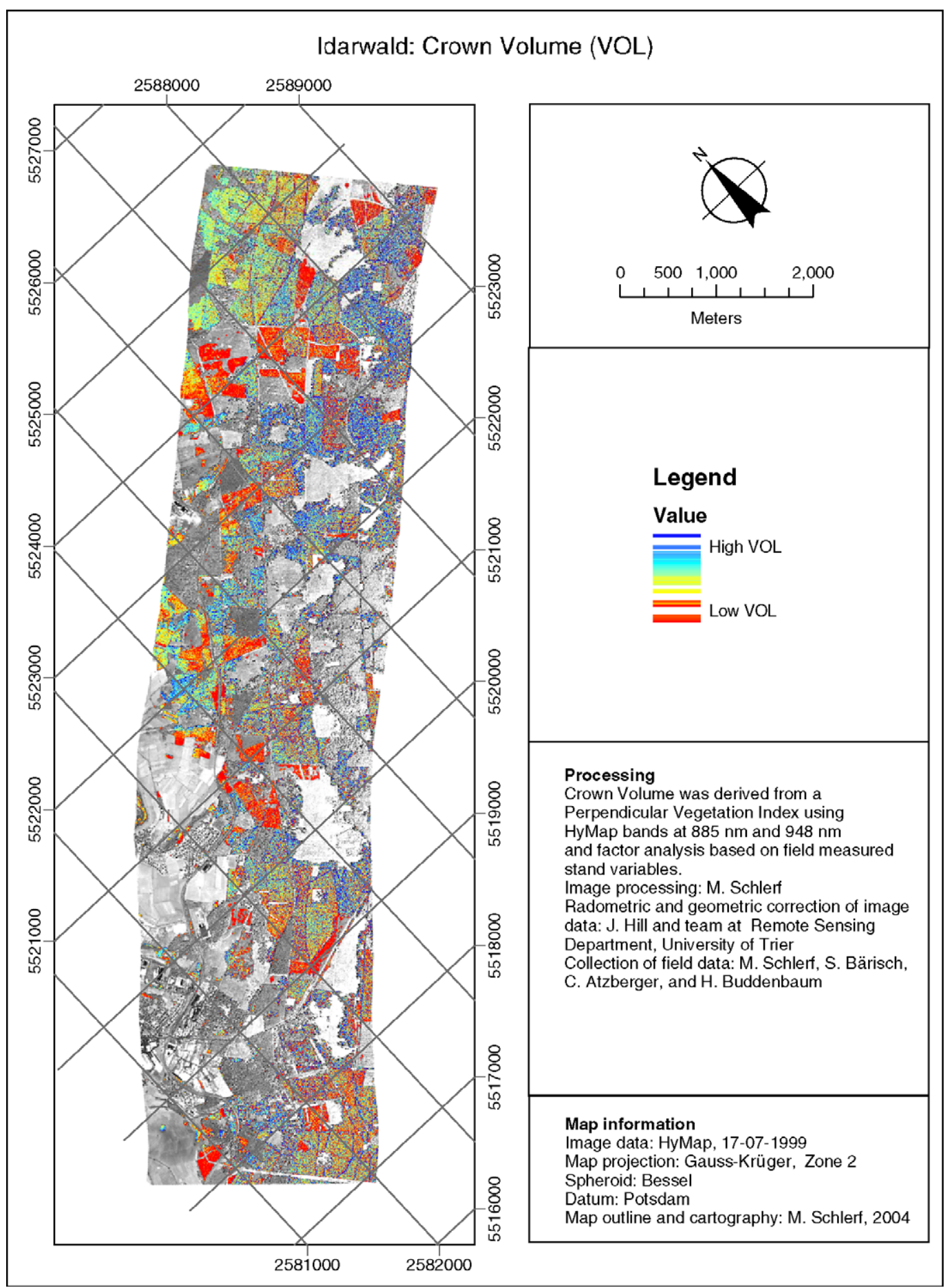

Fig. 11. Map of crown volume at Idarwald.

were computed for 156 forest stands. Stand average LAI was summarised into four age classes (Table 11). Mean LAI is generally decreasing with increasing stand age. All forest stands in the map support the age course of LAI observed for the 40 stands that have been used to calibrate the regression model (Fig. 2) and that were then used to compute the map. Standard deviation of LAI is particularly large for the age class of 31- to 50-year old stands. This class also shows low minimum and large maximum values. The reason for the large variability of the 31- to 50 -year old stands is that some stands of this age may be subjected to thinning measures while others may remain undisturbed and thinned at a later stage (Section 3.1).

The LAI map is a valuable resource. It was integrated into the local Forest-GIS of Idarwald. Stand LAI may serve to parameterise coarse scale ecological models (e.g., Biome- 
Table 11

Summary statistics for leaf area index in five age classes

\begin{tabular}{llllll}
\hline Stand age [years] & $n$ & \multicolumn{4}{c}{ Leaf Area Index $\left[\mathrm{m}^{2} \mathrm{~m}^{-2}\right]$} \\
\cline { 3 - 6 } & & Mean & $\begin{array}{c}\text { Standard } \\
\text { deviation }\end{array}$ & Minimum & Maximum \\
\hline $11-30$ & 24 & 5.2 & 0.7 & 3.3 & 6.8 \\
$31-50$ & 46 & 3.7 & 0.9 & 1.9 & 6.7 \\
$51-80$ & 41 & 3.1 & 0.6 & 2.2 & 4.6 \\
$\geq 81$ & 45 & 2.6 & 0.4 & 1.7 & 3.9 \\
\hline
\end{tabular}

BGC) that are used to simulate net primary production and carbon, nutrient and water cycling. The crown volume map may help to assess the amount of standing biomass in support of forest inventory procedures. Although remote sensing methods rarely play a role in operational inventory procedures, it may overcome certain limitations of traditional inventory practices.

\section{Conclusions}

This research intended to explore whether hyperspectral data may improve estimation of biophysical forest variables compared to multispectral data. Several narrow band and broadband vegetation indices were compared. The following conclusion were drawn from this study:

- Forest leaf area index (LAI) and crown volume (VOL) were estimated with good accuracy from hyperspectral remote sensing data;

- Orthogonal compared to ratio VI were better suited to characterise forest LAI and crown volume;

- Hyperspectral data contain more information relevant to the estimation of the forest stand variables than multispectral data;

- Best hyperspectral VI in relation with LAI were typically based on wavebands related to prominent water absorption features. However, more investigations are necessary to confirm this result.

In future work we will explore image texture measures applied to HyMap data for characterising forests. Besides traditional measures of texture, geostatstical parameters will be used to derive information about image objects. It is hoped that this object information in addition to the spectral information of single image pixels will allow a better estimation of important biophysical forest stand parameters. Empirical models developed on relatively homogenous forest plantations have to be extended towards mixed stands. For this purpose, the value of high spatial resolution remote sensing data (e.g., Quickbird) has to be evaluated. The rather limited potential of generalisation inherent to empirical models suggests derivation of forest parameters through physically based models. In the next future we plan to use the INFOR model (Atzberger, 2000), a combination of the FLIM, SAIL and LIBERTY models, to derive important forest parameters with an accuracy comparable to that obtained with the empirical regression models.

\section{Acknowledgments}

This research was for the most part financially supported by the German Research Community (DFG) as part of a larger research project (SFB 522). The authors would like to thank Andreas Müller and Andrea Haushold (German Aerospace Center, DLR) for providing the imaging spectrometer data. Many thanks to Patrick Hostert, Thomas Udelhoven, Wolfgang Mehl, Samuel Bärisch and Sebastian Mader for their help with pre-processing of the HyMap data. The authors are particularly grateful to Samuel Bärisch and Henning Buddenbaum for their assistance in the field at Idarwald test site. We greatly acknowledge the compilation of the Forest-GIS by Michael Vohland. We thank Thomas Udelhoven for the valuable guidelines concerning the factor analysis. Finally, the authors would like to thank three anonymous reviewers for their valuable comments and recommendations concerning the manuscript.

\section{References}

Atzberger, C. (2000). Development of an invertible forest reflectance model: The INFOR-model. In M. Buchroithner (Ed.), A decade of trans-European remote sensing cooperation. Proceedings of the 20th EARSeL Symposium, Dresden (pp. 38-44).

Atzberger, C., \& Werner, W. (1998). Needle reflectance of healthy and diseased spruce stands. In M. Schaepman, et al., (Eds.), 1st EARSeL workshop on imaging spectroscopy (pp. 271-283). Zurich: Impression Dumas.

Badhwar, G. D., Macdonald, R. B., Hall, F. G., \& Carnes, J. G. (1986). Spectral characterization of biophysical characteristics in a boreal forest: Relationship between thematic mapper band reflectance and leaf area index for aspen. IEEE Transactions on Geoscience and Remote Sensing, GE-24, 322-326.

Baret, F., Guyot, G., \& Major, D. J. (1989). Crop biomass evaluation using radiometric measurements. Photogrammetria (PRS), 43, 241-256.

Blackburn, G. A. (2002). Remote sensing of forest pigments using airborne imaging spectrometer and LIDAR imagery. Remote Sensing of Environment, 82, 311-321.

Boegh, E., Soegaard, H., Broge, N., Hasager, C. B., Jensen, N. O., Schelde, K., et al. (2002). Airborne multispectral data for quantifying leaf area index, nitrogen concentration, and photosynthetic efficiency in agriculture. Remote Sensing of Environment, 81, 179-193.

Bonham-Carter, G. F. (1988). Numerical procedures and computer program for fitting an inverted Gaussian model to vegetation reflectance data. Computers \& Geosciences, 14, 339-356.

Boyd, D. S., Wicks, T. E., \& Curran, P. J. (2000). Use of middle infrared radiation to estimate the leaf area index of a boreal forest. Tree Physiology, 20, 755-760.

Broge, N. H., \& Mortensen, J. V. (2002). Deriving green crop area index and canopy chlorophyll density of winter wheat from spectral reflectance data. Remote Sensing of Environment, 81, 45-57.

Brown, L., Chen, J. M., Leblanc, S. G., \& Cihlar, J. (2000). A shortwave infrared modification to the simple ratio for LAI retrieval in boreal forests: An image and model analysis. Remote Sensing of Environment, $71,16-25$ 
Canadell, J. G., Mooney, H. A., Baldocchi, D. D., Berry, J. A., Ehleringer, J. R., Field, C. B., et al. (2000). Carbon metabolism of the terrestrial biosphere: A multitechnique approach for improved understanding. Ecosystems, 3, 115-130.

Chen, J. M., \& Cihlar, J. (1996). Retrieving leaf area index of boreal conifer forests using Landsat TM images. Remote Sensing of Environment, 55, $153-162$.

Chen, J. M., Leblanc, S. G., \& Miller, J. R. (1999). Compact airborne spectrographic imager (CASI) used for mapping biophysical parameters of boreal forests. Journal of Geophysical Research, 104, 27945-27959.

Chen, J. M., Pavlic, G., Brown, L., Cihlar, J., Leblanc, S. G., White, H. P., et al. (2002). Derivation and validation of Canada-wide coarseresolution leaf area index maps using high-resolution satellite imagery and ground measurements. Remote Sensing of Environment, $80,165-184$.

Christ, E. P., \& Cicone, R. C. (1984). A physically-based transformation of thematic mapper data - the TM tasseled cap. IEEE Transactions on Geoscience and Remote Sensing, GE-22, 256-263.

Cocks, T., Jenssen, R., \& Stewart, A. (1998). The HyMap airborne hyperspectral sensor: The system, calibration and performance. In M. Schaepman, et al., (Eds.), 1st EARSeL workshop on imaging spectroscopy (pp. 37-42). Zurich: Remote Sensing Laboratories.

Cohen, W. B., Maiersperger, T. K., Gower, S. T., \& Turner, D. P. (2003). An improved strategy for regression of biophysical variables and Landsat ETM+ data. Remote Sensing of Environment, 84, 561-571.

Curran, P. J., Dungan, J. L., \& Gholz, H. L. (1992). Seasonal LAI in slash pine estimated with Landsat TM. Remote Sensing of Environment, 39, $3-13$.

Curran, P. J., Dungan, J. L., Macler, B. A., \& Plummer, S. E. (1991). The effect of a red leaf pigment on the relationship between red edge and chlorophyll concentration. Remote Sensing of Environment, 35, 69-76.

Curran, P. J., Dungan, J. L., \& Peterson, D. L. (2001). Estimating the foliar biochemical concentration of leaves with reflectance spectrometrytesting the Kokaly and Clark methodologies. Remote Sensing of Environment, 76, 349-359.

Danson, F. M., \& Curran, P. J. (1993). Factors affecting the remotely sensed response of coniferous forest plantations. Remote Sensing of Environment, 43, 55-65.

Danson, F. M., \& Plummer, S. E. (1995). Red-edge response to forest leaf area index. International Journal of Remote Sensing, 16, 183-188.

Dawson, T. P., \& Curran, P. J. (1998). A new technique for interpolating the reflectance red edge position. International Journal of Remote Sensing, 19, 2133-2139.

Duckworth, J. (1998). Spectroscopic quantitative analysis. In J. Workman, \& A. W. Springsteen (Eds.), Applied spectroscopy. A compact reference for practitioners (pp. 93-164). San Diego: Academic Press.

Fassnacht, K. S., Gower, S. T., MacKenzie, M. D., Nordheim, E. V., \& Lillesand, T. M. (1997). Estimating the leaf area index of north central Wisconsin forests using the Landsat thematic mapper. Remote Sensing of Environment, 61, 229-245.

Fernandes, R., Miller, J. R., Hu, B., \& Rubinstein, I. G. (2002). A multiscale approach to mapping effective leaf area index in boreal Picea marina stands using high spatial resolution CASI imagery. International Journal of Remote Sensing, 23, 3547-3568.

Fournier, R. A., Mailly, D., Walter, J. -M. N., \& Soudani, K. (2003). Indirect measurements of forest canopy structure from in situ optical sensors. In M. A. Wulder, \& S. E. Franklin (Eds.), Remote sensing of forest environments - concepts and case studies (pp. 77-114). Boston: Kluwer Academic Publishers.

Franklin, S. E., Lavigne, M. B., Deuling, M. J., Wulder, M. A., \& Hunt Jr., E. R. (1997). Estimation of forest leaf area index using remote sensing and GIS data for modelling net primary production. International Journal of Remote Sensing, 18, 3459-3471.

Gao, B. -C., \& Goetz, A. (1990). Column atmospheric water vapour and vegetation liquid water retrievals from airborne imaging spectrometer data. Journal of Geophysical Reseasrch, 95, 3549-3564.
Gemmell, F., Varjo, J., Strandstrom, M., \& Kuusk, A. (2002). Comparison of measured boreal forest characteristics with estimates from TM data and limited ancillary information using reflectance model inversion. Remote Sensing of Environment, 81, 365-377.

Gong, P., Pu, R., Biging, G., \& Larrieu, M. (2003). Estimation of forest leaf area index using vegetation indices derived from Hyperion hyperspectral data. IEEE Transactions on Geoscience and Remote Sensing, $41,1355-1362$.

Gong, P., Pu, R., \& Miller, J. R. (1995). Coniferous forest leaf area index estimation along the Oregon transect using compact airborne spectrographic imager data. Photogrammetric Engineering and Remote Sensing, 61, 1107-1117.

Harman, H. H. (1976). Modern Factor Analysis (3rd ed.). Chicago: University of Chicago Press.

Herwitz, S., Peterson, D. L., \& Eastman, J. R. (1990). Thematic mapper detection of changes in the leaf area of closed canopy pine plantations in Central Massachusetts. Remote Sensing of Environment, $30,129-140$.

Hildebrandt, G. (1996). Fernerkundung und luftbildmessung. Heidelberg: Herbert Wichmann Verlag, 680 pp.

Hill, J. (1993). High precision land cover mapping and inventory with multi-temporal earth observation satellite data-the ardèche experiment. Luxembourg: Office for official publications of the European Communities.

Hill, J., \& Mehl, W. (2003). Georadiometrische aufbereitung multiund hyperspektraler daten zur erzeugung langjähriger kalibrierter zeitreihen. Photogrammetrie, Fernerkundung, Geoinformation, 1/2003, $7-14$.

Hill, J., Mehl, W., \& Radeloff, V. (1995). Improved forest mapping by combining corrections of atmospheric and topographic effects in Landsat TM imagery. In J. Askne (Ed.), Sensors and environmental applications of remote sensing. Proc. 14th EARSeL Symposium, Göteborg, Sweden, 6-8 June 1994 (pp. 143-151). Rotterdam: Balkema.

Hill, J., \& Sturm, B. (1991). Radiometric correction of multi-temporal thematic mapper data for use in agricultural land-cover classification and vegetation monitoring. International Journal of Remote Sensing, $12,1471-1491$.

Horler, D. N., Dockray, M., \& Barber, J. (1983). The red edge of plant leaf reflectance. International Journal of Remote Sensing, 4, 273-288.

Hu, B., Inannen, K., \& Miller, J. R. (2000). Retrieval of leaf area index and canopy closure from CASI data over the BOREAS flux tower sites. Remote Sensing of Environment, 74, 255-274.

Kazimirov, N. I., \& Morozova, R. N. (1973). Biological cycling of matter in spruce forest of Karelia. Leningrad: Nauka, 216 pp.

Kennedy, R. O., Cohen, W. B., \& Takao, G. (1997). Empirical methods to compensate for a view-angle dependent brightness gradient in AVIRIS imagery. Remote Sensing of Environment, 62, 277-291.

Kuusk, A. (1998). Monitoring of vegetation parameters on large areas by the inversion of a canopy reflectance model. International Journal of Remote Sensing, 19, 2893-2905.

Lee, K. -S., Cohen, W. B., Kennedy, R. E., Maiersperger, T. K., \& Gower, S. T. (2004). Hyperspectral versus multispectral data for estimating leaf area index in four different biomes. Remote Sensing of Environment, 91, $508-520$

Long, J. N., \& Smith, F. W. (1992). Volume increment in Pinus contora var. latifolia: The influence of stand development and crown dynamics. Forest Ecological Management, 53, 53-64.

Lucas, N. S., Curran, P. J., Plummer, S. E., \& Danson, F. M. (2000). Estimating the stem carbon production of a coniferous forest using an ecosystem simulation model driven by the remotely sensed red edge. International Journal of Remote Sensing, 21, 619-631.

Pearson, R. L., \& Miller, L. D. (1972). Remote mapping of standing crop biomass for estimation of the productivity of the short-grass prairie, Pawnee National Grasslands, Colorado. Proceedings of the 8th International Symposium on Remote Sensing of Environment (pp. 1357-1381). ERIM International. 
Peddle, D. R., Teillet, P. M., \& Wulder, M. A. (2003). Radiometric image processing. In M. A. Wulder, \& S. E. Franklin (Eds.), Remote sensing of forest environments - concepts and case studies (pp. 181-208). Boston: Kluwer Academic Publishers.

Peterson, D. L., \& Running, S. W. (1989). Application in forest science and management. In G. Asrar (Ed.), Theory and applications of optical remote sensing (pp. 429-473). New York: John Wiley \& Sons.

Peterson, D. L., Spanner, M. A., Running, S. W., \& Teuber, K. B. (1987) Relationship of thematic mapper simulator data to leaf area index of temperate coniferous forests. Remote Sensing of Environment, 22, $323-341$.

Pinar, A., \& Curran, P. J. (1996). Grass chlorophyll and the reflectance red edge. International Journal of Remote Sensing, 17, 351-357.

Richardson, A. J., \& Wiegand, C. L. (1977). Distinguishing vegetation from soil background information. Photogrammetric Engineering and Remote Sensing, 43, 1541-1552.

Rock, B. N., Hoshizaki, T., \& Miller, J. R. (1988). Comparison of in situ and airborne spectral measurements of the blue shift associated with forest decline. Remote Sensing of Environment, 24, 109-127.

Rouse, J. W., Haas, R. H., \& Schell, J. A. (1974). Monitoring the vernal advancement of retrogradiation of natural vegetation. $N A S A / G S F C$, type III, final report (pp. 1-371). Greenbelt, MD: USA.

Running, S. W., Peterson, D. L., Spanner, M. A., \& Teuber, K. B. (1986). Remote sensing of coniferous forest leaf area. Ecology, 67, 273-276.

Schimel, D., Melillo, J., Tian, H., McGuire, A. D., Kicklighter, D., Kittel, T., et al. (2000). Contribution of increasing CO2 and climate to carbon storage by ecosystems in the United States. Science, 287, 2004-2006.

Schläpfer, D., Schaepman, M. E., \& Itten, K. I. (1998). PARGE: Parametric geocoding based on GCP-calibrated auxiliary data. SPIE Int. Symp. on Opt. Sc., Eng. and Instr. (pp. 334-344). San Diego: CA.

Sedlmayer 2004: http://www.sedlmayer.de/holzneu/fichte.htm.

Soudani, K., Trautmann, J., \& Walter, J. -M. N. (2002). Leaf area index and canopy stratification in Scots pine stands. International Journal of Remote Sensing, 23, 3605-3618.

Spanner, M. A., Pierce, L. L., Peterson, D. L., \& Running, S. W. (1990a). Remote sensing of temperate coniferous forest leaf area index - the influence of canopy closure, understory vegetation and background reflectance. International Journal of Remote Sensing, 11, 95-111.

Spanner, M. A., Pierce, L. L., Running, S. W., \& Peterson, D. L. (1990b). The seasonality of AVHRR data of temperate coniferous forests:
Relationship with leaf area index. Remote Sensing of Environment, 33, 97-112.

StatSoft, Inc., 2004: http://www.statsoftinc.com/textbook/stathome.html. Tanré, D., Duhaut, P., Herman, J. J., Perbos, J., \& Deschamps, P. Y. (1990). Description of a computer code to simulate the signal in the solar spectrum: The 5S code. International Journal of Remote Sensing, 11, 659-668.

Teillet, P. M., Staenz, K., \& Williams, D. J. (1997). Effects of spectral, spatial, and radiometric characteristics on remote sensing vegetation indices of forested regions. Remote Sensing of Environment, 61, $139-149$.

Thenkabail, P. S., Smith, R. B., \& De Paw, E. (2000). Hyperspectral vegetation indices and their relationships with agricultural crop characteristics. Remote Sensing of Environment, 71, 158-182.

Tian, Y., Wang, Y., Zhang, Y., Knyazikhin, Y., Bogaert, J., \& Myeni, R. B. (2002). Radiative transfer based scaling of LAI retrievals from reflectance data of different resolutions. Remote Sensing of Environment, 84, 143-159.

Treitz, P. M., \& Howarth, P. J. (1999). Hyperspectral remote sensing for estimating biophysical parameters of forest ecosystems. Progress in Physical Geography, 23, 359-390.

Turner, D. P., Cohen, W. B., Kennedy, R. E., Fassnacht, K. S., \& Briggs, J. M. (1999). Relationships between leaf area index and landsat TM spectral vegetation indices across three temperate zone sites. Remote Sensing of Environment, 70, 52-68.

Valentini, R., Matteucci, G., Dolman, A. J., Schulze, E. -D., Rebmann, C., Moors, E. J., et al. (2000). Respiration as the main determinant of carbon balance in European forests. Nature, 404, 861-865.

Vohland, M. (1997). Einsatz von Satellitenbilddaten (Landsat TM) zur Ableitung forstlicher Bestandsparameter und Waldschadensindikatoren. M. Sc. Thesis. University of Trier.

Vose, J. M., Dougherty, P. M., Long, J. N., Smith, F. W., Gholz, H. L., \& Curran, P. J. (1994). Factors influencing the amount and distribution of leaf area of pine stands. Ecological Bulletins, 43, 102-114.

White, J. D., Running, S. W., Nemani, R., Keane, R. E., \& Ryan, K. C. (1997). Measurement and remote sensing of LAI in rocky mountain montane ecosystems. Canadian Journal of Forest Research, 27, $1714-1727$

Wicks, T. E., \& Curran, P. J. (2003). Flipping forests: Estimating future carbon sequestration of the boreal forest using remotely sensed data. International Journal of Remote Sensing, 24, 835-842. 